\title{
EFEITO DE ALIMENTOS E BEBIDAS NO ESMALTE DENTAL DECÍDUO APÓS DESAFIO EROSIVO COM ÁCIDO CLORÍDRICO
}

Dissertação apresentada à Faculdade de
Odontologia de Ribeirão Preto da Universidade de
São Paulo para obtenção do Grau de Mestre em
Ciências junto ao Programa de Odontopediatria com
Área de Concentração em Odontopediatria.

Orientadora: Profa. Dra. Mônica Campos Serra 
AUTORIZO A REPRODUÇÃO E DIVULGAÇÃO TOTAL OU PARCIAL DESTE TRABALHO, POR QUALQUER MEIO CONVENCIONAL OU ELETRÔNICO PARA FINS DE ESTUDO E PESQUISA, DESDE QUE CITADA A FONTE.

FICHA CATALOGRÁFICA

Mesquita, Késsia Suênia Fidelis

Efeito de alimentos e bebidas no esmalte dental decíduo após desafio erosivo com ácido clorídrico. Ribeirão Preto, 2012.

p. 91 : il. ; $30 \mathrm{~cm}$

Dissertação de Mestrado apresentada à Faculdade de Odontologia de Ribeirão Preto/USP - Área de concentração: Odontopediatria.

Orientadora: Serra, Mônica Campos

1. Erosão dentária. 2. Esmalte. 3. Dente decíduo. 4. Ácido clorídrico. 5. Alimentos. 6. Bebidas 


\section{EFEITO de ALIMENTOS E BebidAs No esmalte deNTAL DEcíduo APÓS DESAFIO EROSIVO COM ÁCIDO CLORÍDRICO}

Dissertação apresentada à Faculdade de Odontologia de Ribeirão Preto da Universidade de São Paulo para obtenção do Grau de Mestre em Ciências.

Data da defesa: 1 I

BANCA EXAMINADORA

Prof(a). Dr(a).:

Julgamento: Assinatura:

$\operatorname{Prof}(a) \cdot \operatorname{Dr}(\mathrm{a})$ :

Julgamento: Assinatura:

Prof(a). Dr(a):

Julgamento: Assinatura: 


\section{KÉSSIA SUÊNIA FIDELIS DE MESQUITA}

Nascimento

Filiação

2004-2009

2009-2011

2009-2012
26/05/1983 - Maceió/AL

Pedro Pinto de Mesquita Filho

Claudia Maria Fidelis de Mesquita

Curso de Graduação em Odontologia

Faculdade de Odontologia da Universidade Federal de Alagoas - FOUFAL/UFAL

Curso de Pós-Graduação em Odontologia (Especialização).

Área de concentração: Odontopediatria

Associação Odontológica de Ribeirão Preto - AORP

Curso de Pós-Graduação em Odontologia (Mestrado).

Área de concentração: Odontopediatria

Faculdade de Odontologia de Ribeirão Preto FORP/USP 


\section{DEDICATÓRIA}

A Deus...

Pela graça da vida...

Pela oportunidade que me é dada todos os dias para ser feliz...

Pela família que me proporcionou ter...

Pelos amigos sinceros que me presenteou...

Pelo caminho saudável que me guia...

Pelas conquistas alcançadas...

E pelas vitórias que estão por vir!

"Mais importante que o lugar que ocupas em mim, é a intensidade de Tua presença em tudo que faço. " Ana Cláudia Soranzo

Aos meus queridos pais, Claudia Maria Fidelis de Mesquita e Pedro

Pinto de Mesquita Filho...

Pelo amor incondicional...

Por acreditarem nos meus sonhos e me incentivarem a lutar por eles!

Imagino o quanto deve ser difícil superar o vazio deixado pelos filhos ao saírem de casa, mas também imagino o quão satisfatório deve ser vê-los conquistando seu espaço... Obrigada por todo amor e dedicação! 
Às minhas irmãs Keysse Suelen Fidelis de Mesquita e

Kyssia Suedna Fidelis de Mesquita...

Pelo carinho, amizade, cumplicidade, incentivo...

Pelos momentos compartilhados e por acreditarem nos meus ideais!

Aos meus avós, Luzenita Fidelis de Lima e Cícero Carlos de Lima..

Obrigada pela experiência de vida compartilhada e pelo amor incondicional. Amo demais vocês!

Ao meu noivo Aryel Alves Guimarães...

Por tornar os meus dias mais completos...

Por me fazer tão feliz com seu amor e carinho...

Por sua dedicação, respeito, incentivo, paciência e compreensão...

Obrigada pela força, pelos abraços de conforto e por entender a

distância física que ainda nos separa! Amo você!!!

“A cada passo, um desafio...

A cada desafio, uma vitória...

A cada vitória, um novo passo rumo ao sucesso!"

Michele Bertoletti 


\section{AGRADECIMENTOS ESPECIAIS}

À minha orientadora Professora Dra. Mônica Campos Serra, pelos ensinamentos, acolhimento, dedicação e confiança. Obrigada pelo conhecimento científico compartilhado! Orguโho-me em tê-la como orientadora. Com certeza levarei sempre comigo seu exemplo de ética profissional!

À minha coorientadora Professora Dra. Maria Cristina Borsatto, por sua alegria constante e sua disposição em querer sempre ajudar. Obrigada por sua amizade, pela forma tão especial que me acolhe e por ter me adotado assim que cheguei à FORP. Você tem eternamente minha admiração e carinho!

Ao Professor Dr. Milton Fernando de Andrade Silva e ao Professor Dr. Natanael Barbosa dos Santos por terem me proporcionado a experiência da pesquisa científica e me incentivado a buscar esse caminho! 


\section{AGRADECIMENTOS}

Aे Faculdade de Odontologia de Ribeirão Preto da Universidade de São Paulo, na pessoa do atual diretor Prof. Dr. Valdemar Mallet da Rocha Barros.

À Coordenação do Curso de Pós-Graduação em Odontopediatria da Faculdade e Odontologia de Ribeirão Preto da Universidade de São Paulo, na pessoa da Coordenadora Profa. Dra. Léa Assed Bezerra da Silva e do Vice-Coordenador Prof. Dr. Paulo NelsonFifho.

Aos Professores do Departamento de Clínica Infantil, Odontologia Preventiva e Social da Faculdade de Odontologia de Ribeirão Preto da Universidade de São Paulo, Profa. Dra. Aldevina Campos de Freitas, Profa. Dra. Alexandra Mussolino de Queiroz, Profa. Dra. Kranya Victória Diaz Serrano, Profa. Dra. Léa Assed Bezerra da Silva, Profa. Dra. Maria Cristina Borsatto, Prof. Dr. Paulo Nelson-Filho, Profa. Dra. Raquel Assed Bezerra da Silva, Profa. Dra. Sada Assed, Prof. Dr. Adilson Thomazinho, Prof. Dr. Fábio Lourenço Romano, Prof. Dr. José Tarcísio Lima Ferreira, Profa. Dra. Maria Bernadete Sasso Stuani e Profa. Dra. Mírian Aiko Nakane Matsumoto.

Profa. Dra. Aldevina Campos de Freitas, sua dedicação e amor aos pacientes são admiráveis. Obrigada por compartilhar sua sabedoria! 
Profa. Dra. Alexandra Mussolino de Queiroz, obrigada pelo acolhimento e pela forma carinhosa que sempre me recebeu. Suas palavras de incentivo foram essenciais ao longo desta caminhada!

Profa. Dra. Andiara De Rossi, obrigada pela sua amizade sincera, carinho, incentivo e parceria ao longo do curso. Agradeço também pelas palavras de incentivo e por acreditar no meu potencial!

Profa. Dra. Kranya Victória Diaz Serrano, obrigada pela agradável convivência, por sua alegria e pela sua disposição em querer sempre ajudar!

Profa. Dra. Léa Assed Bezerra da Silva, obrigada pela oportunidade que me foi dada em poder fazer parte do programa de mestrado em odontopediatria da FORP. Tenho plena convicção do amadurecimento profissional que estou trilhando ao lado de vocês!

Prof. Dr. Paulo Nelson-Filho, obrigada por seus ensinamentos, dedicação, apoio e atenção no decorrer do curso. Você é um professor exemplar e espero poder repassar tudo que venho aprendendo ao seu lado! 
Profa. Dra. Raquel Assed Bezerra da Silva, obrigada pela sua amizade, carinho, cumplicidade e ajuda nos momentos que precisei. Espero que ainda possamos compartilhar muitos momentos juntas!

Aos funcionários do Departamento de Clínica Infantil, Odontologia Preventiva e Social da Faculdade de Odontologia de Ribeirão Preto da Universidade de São Paulo, Benedita Viana Rodrigues, Carmo Eurípedes Terra Barreto, Dra. Carolina Paes Torres Montavani, Dorival Gaspar, Fátima Jacinto Daniel, Fátima Aparecida Rizoli, Filomena Lelli Placciti, Dr. Francisco Wanderley Garcia de Paula e Silva, José Aparecido Jeves do Nascimento, Marco Antônio dos Santos, Matheus Morelli Zanela, Micheli Cristina Leite Rovanholo, Nilza Letícia Magalhães, Renata Aparecida Fermandes e Vera Ribeiro do Nascimento pela paciência e agradável convivência.

Micheli Cristina Leite Rovanholo, obrigada pela simpatia que sempre me recebeu, por sempre estar à disposição em ajudar e por ser uma pessoa iluminada!

Às funcionárias da Seção de Pós-Graduação da Faculdade de Odontologia de Ribeirão Preto da Universidade de São Paulo, Isabel Cristina Galino Sola e Regiane Cristina Moi Sacilotto, pela atenção dada durante o período do curso. 
Aos amigos da Pós-Graduação, Ana Caroline Fumes, Ana Zilda Nazar Bergamo, Bárbara Jarreta, Camila Scatena, Cíntia Guimarães de Almeida, Claudia de Castro Rizzi Maia, Cristhiane Ristum Bagattin Rossi, Cristina Bueno Brandão, Daniele Luca Longo, Danielle Torres Azevedo, Danielly Cunha Araújo Ferreira, Denise de Souza Matos, Driely Barreiros, Elaine Machado Pingueiro, Fabrício Kitazono de Carvalho, Fernanda Regina Ribeiro Santos, Francisco Carlos Rehder Neto, Giselle de Angelo Leite Carbonaro Guerreiro, Iliana Ferraz Sab6attini, Iria de Fátima Lopes Peixoto Dutra, Karina Alessandra Michelão Grecca Pieroni, Katharina Morant Holanda de Oliveira, Kleber Cortês Bonifacio, Larissa Moreira Spinola de Castro Raucci, Larissa Nogueira Soares Ribeiro, Leonardo Bíscaro Pereira, Ligia Maria Napolitano Gonçalves, Marcela C. D. Andrucioli, Marcela Martin Del Campo Fierro, Mariana Alencar Nemezio, Marília Pacífico Lucisano, Marina Fernandes de Sena, Maristela Soares Swerts Pereira, Marta Maria Martins Giamatei Contente, Maya Fernanda Manfrin Arnez, Milena Silva Campos, Priscilla Coutinho Romualdo, Regina Aparecida Segatto Saiani, Rodrigo Alexandre Valério, Rodrigo Teixeira Macri, Silvana Aparecida Fernandes Polizeli, Soraya Cheier Di6 Gonçalves, Tatiana dos Santos Ciccone de Faria e Walter Raucci Neto, pelos momentos compartilhados.

Camila Scatena, obrigada pela atenção e ajuda no decorrer da execução deste trabalho. Você é uma mulher guerreira, um exemplo de força e superação! 
Cíntia Guimarães de Almeida, meu carinho e admiração por você aumentam a cada dia. Você é uma pessoa iluminada e agradeço a Deus por colocar pessoas como você no meu caminho. Tenha certeza que suas palavras sempre sensatas e carinhosas, sua doçura e afeto me tornaram mais forte durante esta caminhada. Obrigada por ser uma pessoa tão especial!

Marília Pacífico Lucisano, nem sei como agradecer essa amizade tão pura e sincera. Você e sua família me acolheram como se eu fosse parte dela. Sinto-me honrada em receber um carinho tão especial vindo de vocês. Agradeço inclusive em nome da minha família, por todo acolhimento proporcionado. Com certeza meus dias foram mais felizes e leves com sua amizade. Obrigada por ter sorrido e chorado junto comigo, pelo ombro amigo e pelas palavras sempre carinhosas! Má, você é muito especial!

Marina Fernandes de Sena, obrigada pela amizade,
companheirismo e agradável convívio! Nossas tardes tomando
cappuccino e nossas gargalhadas serão sempre lembradas.

À amiga Paula Dariana Fernandes Ferreira, por tudo que fez por mim! Qualquer agradecimento será pouco diante de todo acolhimento. Obrigada por sempre ter cuidado de mim como se fosse uma irmã, por todos os favores, caronas, almoços e por sua alegria constante! Agradeço também, em nome da minha família, por ter encontrado um anjinho por aqui. Dari, você é uma amiga mais que especial! 
À amiga Cristiane Tomaz Rocha, pela amizade construída, pelo companheirismo, por todas as gargalhadas e pela confiança depositada em mim. Saudades Ju!

À amiga conterrânea Cristine $D^{\prime}$ almeida Borges, pela amizade construída, pelos agradáveis momentos compartilhados, pelo bom humor e por me fazer sentir tão próxima de casa.

À Patrícia Marchi, técnica do laboratório de Dentística, pelo carinho, amizade, gargalhadas e auxílio durante a execução do experimento. Paty, muito obrigada!

Aos amigos do Departamento de Odontologia Restauradora Ana Bárbara, César Lepri, Daniel Galafassi, Júlia, Juliana Jendiro6a Faraoni Romano, Renata Siqueira Scatolin, Taísa Penazzo Lepri.

Ao Prof. Dr. Antônio Luiz Rodrigues Júnior, pelo auxílio, disponibilidade e orientação da análise estatística dos resultados.

À CAPES (Coordenação de Aperfeiçoamento de Pessoal de Nível Superior) pela bolsa concedida.

À Faculdade de Odontologia da Universidade Federal de Alagoas - FOUFAL e aos meus eternos mestres, por terem feito parte do meu processo de aprendizagem. 
As minhas amigas de Maceió Katherine Maria de Araújo Veras, Joanna Manoela Castello Branco Evaristo de Paiva, Lanusia Nunes Almeida, Liliane Santana Araújo, Mayara Costa Neves Rocha, Milene Reis de Santana, Renata de Melo Franco, Suzana Caroline Vieira de Menezes e Viviane da Hora Dantas, pelo incentivo e por sempre torcerem por mim!

Katherine Maria de Araújo Veras, você é um exemplo de garra e determinação. Obrigada pela sua fiel amizade!

Liliane Santana Araújo, Mayara Costa Neves Rocha, Milene Reis de Santana e Viviane da Hora Dantas, obrigada pelos momentos agradáveis, pelas gargalhadas e torcida sempre!

Renata de Melo Franco, agradeço a Deus por ter uma amiga tão iluminada em minha vida. Admiro muito você!

Suzana Caroline Vieira de Menezes, o que seria de mim se não existisse sua amizade ao longo dos meus dias? Obrigada por estar sempre presente em minha vida, compartifhando as derrotas e vitórias e por ser essa amiga-irmã tão especial. Obrigada por ter ouvido minhas angústias, minhas alegrias e por ter me incentivado a sempre olhar para frente! 
"Sou um pouco de todos que conheci,

Um pouco dos lugares que fui,

Um pouco das saudades que deixei,

Sou muito das coisas que gostei.

Entre umas e outras errei.

Entre muitas e outras conquistei!"

Ramon Hasman 
MESQUITA, KSF. Efeito de alimentos e bebidas no esmalte dental decíduo após desafio erosivo com ácido clorídrico. 91p. [dissertação]. Faculdade de Odontologia de Ribeirão Preto, Universidade de São Paulo, Ribeirão Preto. 2012.

O objetivo deste estudo foi avaliar o efeito, in vitro, de alguns alimentos e bebidas industrializados oferecidos como lanche às crianças, sobre o esmalte dental decíduo, após simulação de desafio erosivo intrínseco em função do tempo de exposição. A coroa de cento e dois incisivos decíduos hígidos foram fixadas em bases acrílicas, expondo-se uma área de $2 \mathrm{~mm}$ de diâmetro da superfície vestibular. Os espécimes foram submetidos a um desafio erosivo com ácido clorídrico e divididos aleatoriamente em 6 grupos $(n=17)$ : Leite Achocolatado Toddynho (Pepsico) - controle negativo, Petit Suisse Danoninho (Danone), logurte de Morango (Vigor), Papinha de Maçã (Nestlé), Leite Fermentado Yakult (Yakult) e Suco de Laranja Caseira com Gominhos (del Valle) - controle positivo. Os ciclos de imersão nos produtos teste foram realizados durante 28 dias, $2 x / d i a$, intercalados com saliva artificial. Medidas de microdureza superficial do esmalte foram realizadas inicialmente (baseline), após imersão em ácido clorídrico e com 7, 14, 21 e 28 dias de experimento. A Análise de Variância (ANOVA) a dois critérios, seguida pela decomposição da soma dos quadrados e pelo teste de Tukey apresentou diferença significativa a interação entre Lanches e Tempo $(p=0.0000)$. O suco de laranja foi o produto que resultou em maior perda mineral do esmalte aos 28 dias. Nenhum dos lanches utilizados foi capaz de recuperar a microdureza do esmalte dental decíduo ao longo do tempo final de exposição (28 dias). A análise qualitativa por meio de Microscopia Eletrônica de Varredura foi realizada ao término dos 28 dias de exposição aos produtos, observando-se destruição generalizada dos prismas de esmalte dos dentes decíduos.

Palavras-chave: erosão dentária, esmalte, dente decíduo, ácido clorídrico, alimentos, bebidas. 


\section{MESQUITA, KSF. Effect of food and beverages in deciduous tooth enamel after erosive} challenge with hydrochloric acid. 91p. [dissertation]. Ribeirão Preto: FORP - University of São Paulo, 2012.

The objective of this study was to evaluate the effect in vitro of some industrialized foods and beverages offered to children as a snack, in enamel deciduous teeth after simulation of erosive intrinsic challenge inherent function of time of exposure. The crowns of one hundred and two deciduous incisor teeth were fixed on acrylic bases, setting up an area of $2 \mathrm{~mm}$ diameter of the buccal surface. The specimens were subjected to an erosive challenge with hydrochloric acid and randomly divided into 6 groups $(n=17)$ : Chocolate Milk Toddynho (Pepsico) - negative control, Petit Suisse Danoninho (Danone), Strawberry Yogurt (Vigor), apple pap (Nestlé), Fermented Milk Yakult (Yakult) and Orange Juice Home Squeezed Style (del Valle) - positive control. The cycles of immersion in the test products were made during 28 days, $2 x /$ day, interspersed with artificial saliva. Measurements of microhardness of enamel were performed initially (baseline), after immersion in hydrochloric acid and 7, 14, 21 and 28 days of experiment. A two-away ANOVA according split-plot design, followed by decomposition of the sum of the squares and the Tukey test, revealed significant effect for interaction between Time and Snacks $(p=0.0000)$. The orange juice was the product that resulted in greater mineral loss of enamel after 28 days. None of the snacks used was able to recover the microhardness of the deciduous tooth enamel over time end of exposure ( 28 days). Qualitative analysis by Scanning Electron Microscopy was performed at the end of 28 days of exposure to products, noting the widespread destruction of enamel rods of deciduous teeth.

Keywords: dental erosion, enamel, deciduous tooth, hydrochloric acid, food, drink. 


\section{SUMÁRIO}

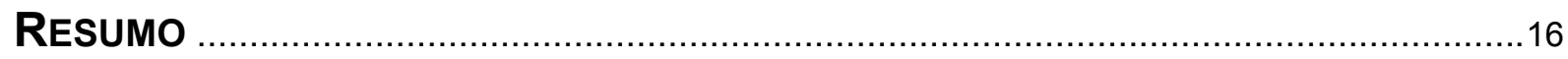

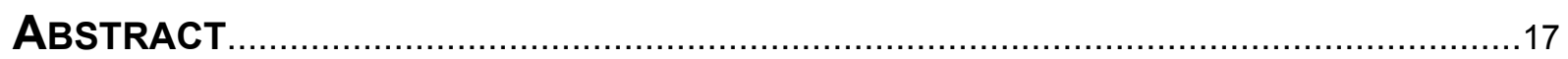

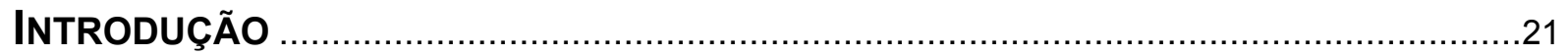

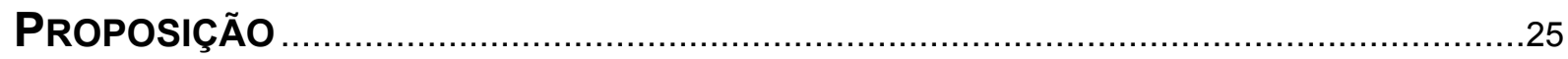

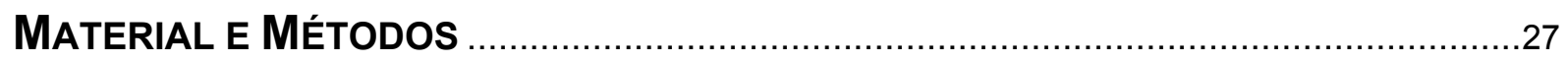

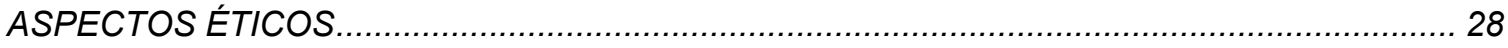

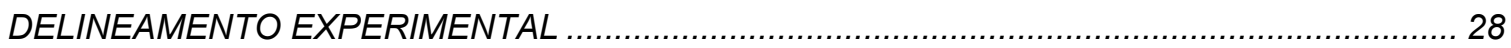

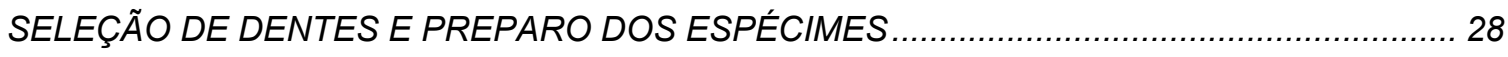

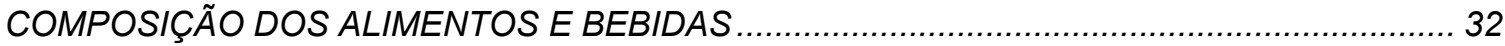

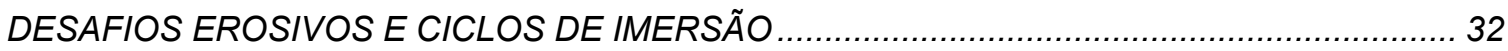

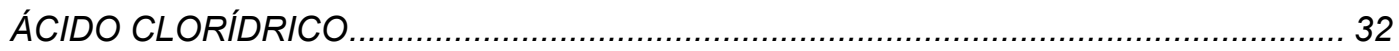

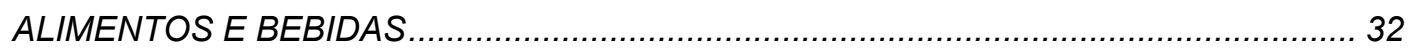

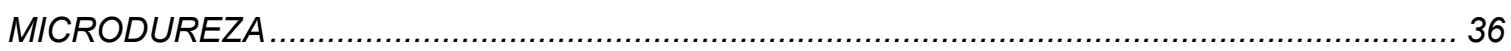

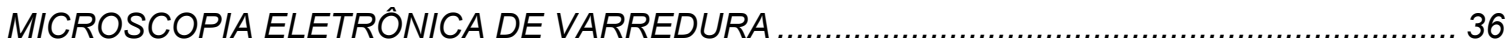

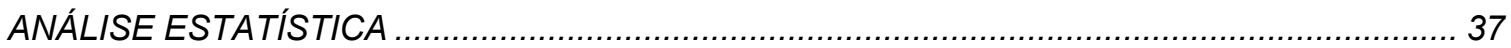

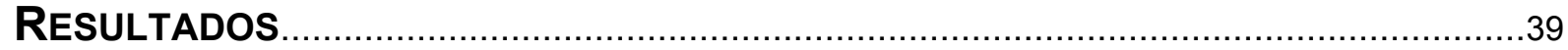

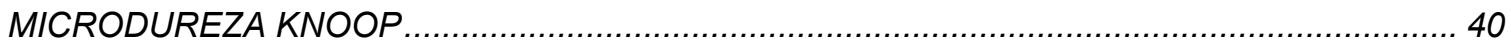

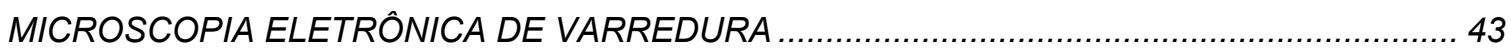

DISCUSSÃO

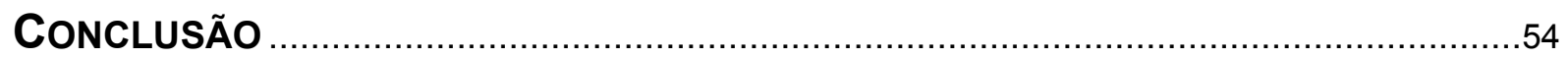

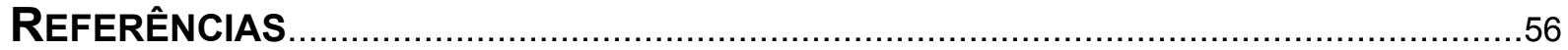

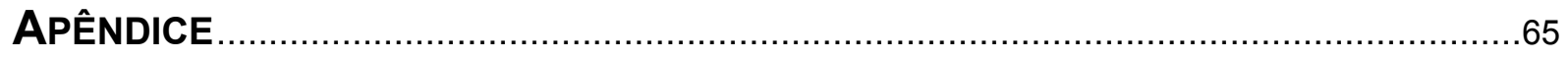

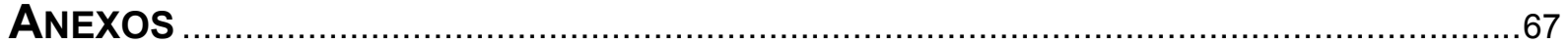


INTRODUÇÃO 
A nutrição adequada durante a infância é essencial para garantir o crescimento, a saúde e o desenvolvimento da criança (WHO, 2009). A partir do sexto mês de vida do bebê, alimentos e líquidos são introduzidos (Imdad et al., 2011; PAHO, 2003; WHO, 2003) preferencialmente na forma de papas e sucos (Sociedade Brasileira de Pediatria, 2006), aumentando-se gradualmente a consistência e a frequência de consumo com a idade (WHO, 2009).

Os sinais de fome e saciedade da criança devem ser observados. Além das refeições principais, podem ser oferecidos lanches, que são alimentos práticos e fáceis de preparar, consumidos entre as refeições, em média duas vezes ao dia (Sociedade Brasileira de Pediatria, 2006; WHO, 2009). Os alimentos industrializados são opções práticas por serem facilmente transportados (Hurley e Black, 2010), porém, o consumo inadequado, em excesso e muito frequente pode ser prejudicial durante a infância (Aquino e Philippi, 2002) e na idade adulta (Aquino e Philippi, 2002).

Problemas de saúde bucal, como a erosão dental, podem ser causados por alimentos e bebidas ácidas (Järvinen et al., 1991; Lussi et al., 2011). A erosão dental é a perda crônica de substância dentária (Jitpukdeebodintra et al., 2010) na presença de ácidos, sem envolvimento de bactérias (Nunn, 1996; Lussi et al., 2011), caracterizada clinicamente como desgaste corrosivo abrasivo (Serra et al., 2009). É uma condição de etiologia complexa e multifatorial (Lussi et al., 2011) comum em crianças e adolescentes (Lussi et al., 2007), no qual o contato de ácidos com a estrutura dentária pode ser decorrente de fatores intrínsecos, como vômitos, regurgitação e refluxo gastroesofágico (Bartlett et al., 1996; Shaw e Smith, 1998) e/ou extrínsecos (Lussi e Jaeggi, 2006), como fontes industriais (Addy e Shellis, 2006), uso de medicamentos e dieta (Lussi e Jaeggi, 2006).

O refluxo gastroesofágico é um processo fisiológico, comum em pacientes pediátricos (Alfaro et al., 2008), caracterizado pela passagem involuntária (Davies e Sandhu, 1995) do conteúdo estomacal pelo esôfago (Alfaro et al., 2008) até a cavidade bucal 
(Bartlett, 2006). Esse quadro é considerado patológico com o aumento da frequência e intensidade, causando a doença do refluxo gastroesofágico (Davies e Sandhu, 1995).

Apesar do ácido clorídrico, presente no suco gástrico, provocar desmineralização e perda de tecido dental duro (Bartlett, 2006), a dieta é o principal fator causador da erosão dental (Moynihan, 2005; Lussi et al., 2011) devido ao alto consumo de alimentos e bebidas ácidas (Lussi et al., 2000). O potencial erosivo vai depender do pH, concentração de ácidos,

duração do tempo de exposição (Larsen e Nyvad, 1999), acidez titulável, conteúdo mineral, clearance da superfície e propriedade quelante (Lussi e Jaeggi, 2008).

Em busca de oferecer lanches práticos às crianças, os cuidadores têm optado por produtos industrializados, dentre eles: iogurtes, leites fermentados, petit suisses, papinhas de frutas, sucos e leites achocolatados. Na literatura, os resultados sobre o efeito erosivo do iogurte são conflitantes. Enquanto alguns autores afirmam que o iogurte, apesar do $\mathrm{pH}$ ácido, não tem potencial (Lussi et al., 2000; Caglar et al., 2006; Kargul et al., 2007), nem efeito erosivo (Rytömaa et al., 1988; Caglar et al., 2005; Wongkhantee et al., 2006; Waterhouse et al., 2008), existe relato que o iogurte aumenta significativamente o desgaste e reduz a microdureza do esmalte (Jitpukdeebodintra et al., 2010). Em estudo recente, bebidas lácteas fermentadas, ricas em Lactobacillus ou Bifidobacterium, utilizadas na prevenção e tratamento de transtornos gastrointestinais (Haukioja, 2010) provocaram perda mineral superficial em esmalte bovino após ciclos de desmineralização e remineralização (Lodi et al., 2010). Embora seja um alimento bastante consumido pelas crianças, não existem trabalhos sobre o efeito, em dente, do petit suisse danoninho, um queijo fresco, rico em minerais, vitaminas e polpa de frutas a partir da pasteurização e fermentação do leite. As papinhas de frutas são alimentos pastosos práticos, oferecidos às crianças em colheradas, porém, não existem estudos que tenham avaliado o potencial e/ou efeito erosivo. Estudos sobre desgaste erosivo apontam o suco de laranja com alto potencial (Hunter et al., 2009) e 
efeito erosivo (Rytömaa et al., 1988; Larsen e Nyvad, 1999; Lussi et al., 2000; Lussi e Hellwig, 2001; Wang et al., 2008; Wongkhantee et al., 2006; Jitpukdeebodintra et al., 2010; Torres et al., 2010), porém apesar de ser uma bebida ácida ainda é bastante consumida por ser considerada mais saudável. Por outro lado, alimentos e bebidas contendo leite e, portanto com alto teor de cálcio e fosfato, como achocolatados, têm maior probabilidade de causar um efeito remineralizante (Amaechi e Higham, 2005) no esmalte dental.

Devido ao consumo constante desses alimentos e bebidas infantis e à escassez de estudos na literatura, faz-se necessário avaliar o efeito erosivo sobre o esmalte dental já erodido com ácido clorídrico, proveniente de refluxo gastroesofágico, em dentes decíduos. 
PROPOSIÇÃO 
Os objetivos do presente estudo foram:

- Avaliar, in vitro, o efeito erosivo de alimentos e bebidas industrializados sobre o esmalte dental de dentes decíduos, após desafio erosivo com ácido clorídrico em função do tempo de exposição.

- Avaliar, qualitativamente, as alterações superficiais do esmalte de dentes decíduos, após o desafio erosivo com ácido clorídrico seguido da imersão nos diferentes alimentos e bebidas, no tempo final de exposição. 
MATERIAL EMÉTODOS 


\section{Aspectos éticos}

O experimento foi realizado em esmalte dental de incisivos decíduos, selecionados e doados pelo Banco de Dentes Humanos da Faculdade de Odontologia de Ribeirão Preto da Universidade de São Paulo, tendo sido submetido e aprovado pelo Comitê de Ética em Pesquisa da Faculdade de Odontologia de Ribeirão Preto/USP (Processo 2011.1.1012.58.7) (Anexo A).

\section{Delineamento experimental}

Os fatores em estudo foram lanches (alimentos ou bebidas infantis) em seis níveis: Controle Negativo [Leite Achocolatado Toddynho (Pepsico)], Controle Positivo [Suco de Laranja Caseira com Gominhos (del Valle)], Papinha de Maçã (Nestlé), logurte de Morango (Vigor), Leite Fermentado Yakult (Yakult), Petit Suisse Danoninho (Danone) e tempo de imersão em seis níveis (inicial ou baseline, após imersão em $\mathrm{HCl}, 7,14,21$ e 28 dias).

O delineamento do estudo foi realizado em blocos completos casualizados, sendo a amostra composta por 102 incisivos decíduos (unidade experimental), divididos aleatoriamente em 6 grupos $(n=17)$.

A variável de resposta quantitativa utilizada foi microdureza Knoop (KNH). Também foi realizada avaliação qualitativa por microscopia eletrônica de varredura (MEV).

\section{Seleção dos dentes e preparo dos espécimes}

Cento e dois incisivos decíduos (Figura 1A) foram armazenados em timol a 0,1\% (Amaechi et al., 1998) a $4^{\circ} \mathrm{C}$ por 48 horas (Messias et al., 2010) para desinfecção e fixação dos mesmos. Em seguida, foram limpos com curetas periodontais tipo Gracey e submetidos à profilaxia com pedra pomes e água, utilizando-se escova de Robinson.

Os dentes foram analisados em lupa estereoscópica ${ }^{1}$ com aumento de $20 x$ e aqueles que apresentavam trincas ou anomalias de estrutura foram descartados. As raízes, quando presentes, foram seccionadas na junção amelocementária em máquina de corte ${ }^{2}$ (Figura 1B) 
sob refrigeração à água e as superfícies palatinas, desgastadas com ponta diamantada $1092^{3}$ em alta rotação ${ }^{4}$ (Figura 1 ) $)$. As coroas foram incluídas no orifício central $(0,8 \mathrm{~cm}$ de diâmetro e 0,35 cm de profundidade) de uma base de resina acrílica $(1,5 \mathrm{~cm} \times 1,5 \mathrm{~cm} \times 1$ $\mathrm{cm}$ ) com cera utilidade ${ }^{5}$, mantendo-se a superfície vestibular paralela com o auxílio de um paralelômetro ${ }^{6}$ (Figura 1D). Em seguida, a fixação das coroas foi complementada com cera para escultura ${ }^{5}$, utilizando-se um gotejador elétrico ${ }^{7}$ (Figura 1E).

O esmalte dental de cada espécime foi planificado com lixas de $\mathrm{Al}_{2} \mathrm{O}_{3}{ }^{8}$ de granulação decrescente (600 e 1200) e polido em pasta abrasiva de alumina de $0,3 \mu^{9}$ em disco de feltro ${ }^{9}$ sob refrigeração com água em politriz giratória ${ }^{10}$ (Figura $1 \mathrm{~F}$ ). Após essa etapa, os espécimes foram lavados em água destilada e submetidos ao ultrassom ${ }^{11}$ (Figura 1G) durante 10 minutos em água destilada para remoção dos resíduos. Na superfície planificada de cada espécime foi delimitada uma área circular de $2 \mathrm{~mm}$ de diâmetro por meio de uma fita adesiva isolante ${ }^{12}$ (Figura $\left.1 \mathrm{H}\right)$ confeccionada com um perfurador.

Os conjuntos dente/base acrílica foram impermeabilizados com duas camadas de esmalte cosmético para unhas (Figura 11). Após secagem, as fitas adesivas foram removidas, expondo-se a área delimitada (Figura 1J).

Os espécimes foram numerados e distribuídos aleatoriamente em 17 blocos completos e casualizados (Montgomery, 1984) e permaneceram em 100\% de umidade relativa a $37^{\circ} \mathrm{C}$ (Messias et al., 2008) até a etapa experimental.

\footnotetext{
${ }^{1}$ Carl Zeiss Jena, EUA

${ }^{2}$ Isomet 5000, Germany

${ }^{3}$ KG Sorensen, Dinamarca

${ }^{4} \mathrm{KaV}$ do Brasil Ind. Com. Ltda, Brasil

${ }^{5}$ Kota Ind. Com. Ltda, Brasil

${ }^{6}$ EIQuip, São Carlos, Brasil

${ }^{7}$ Guelfi Equipamentos, Brasil

${ }^{8}$ Norton Saint-Gobain, Brasil

${ }^{9}$ Buheler, EUA

${ }^{10}$ Phonix $ß$ - Buehler, EUA

${ }^{11}$ Cleaner, Odontobrás, Brasil

${ }^{12}$ Scotch, 3M do Brasil Ltda, Brasil
} 
Figura 1. Seleção e preparação dos espécimes
A. Incisivo decíduo
B. Secção da junção amelocementária
C. Desgaste da superfície palatina
D. Paralelômetro
E. Fixação da coroa
F. Politriz
G. Ultrasson
H. Área circular delimitada
I. Conjunto dente/base acrílica
J. Conjunto dente/base acrílica com área delimitada
K. Estufa 

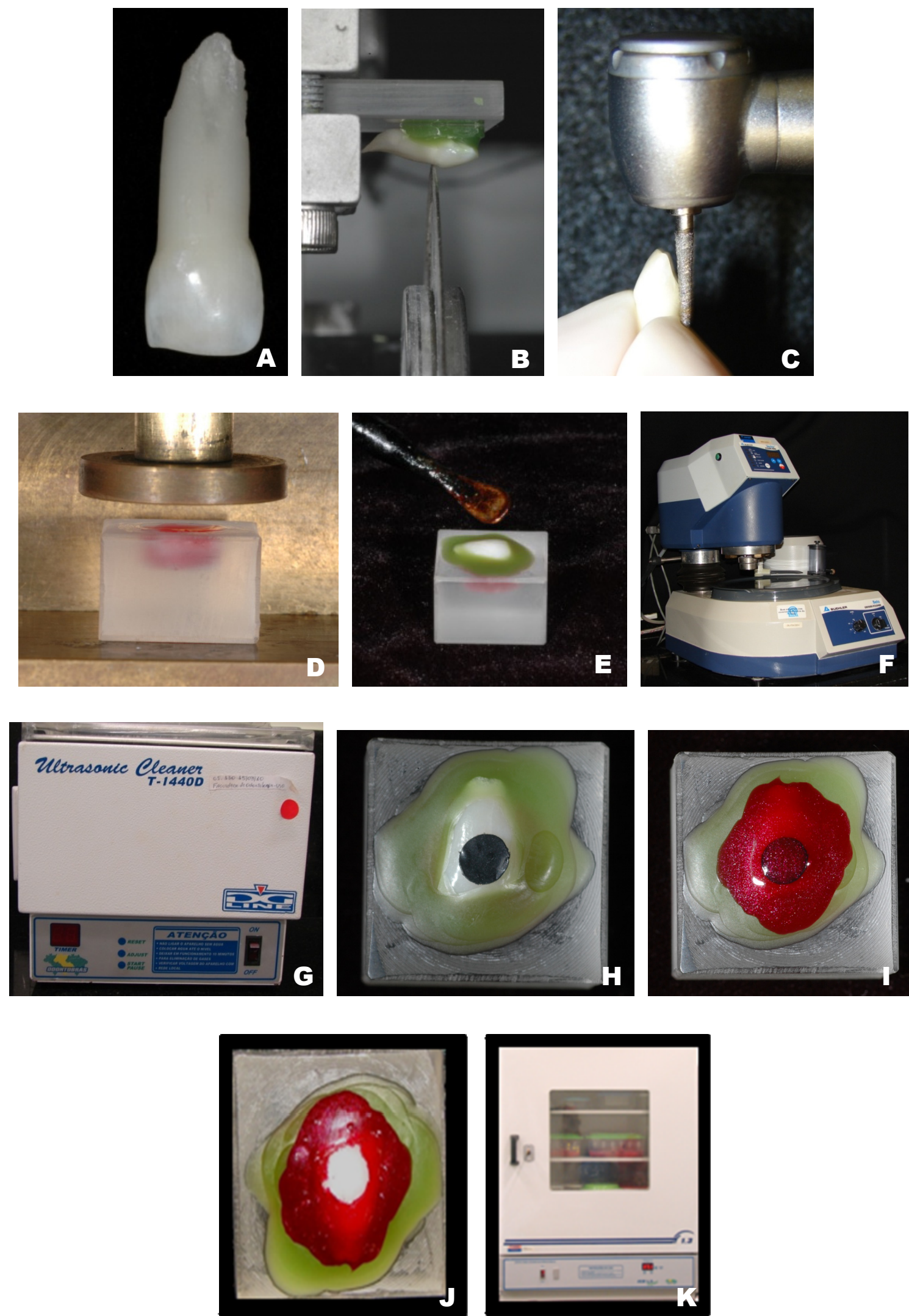

Vinte e quatro horas antes do início dos ciclos, os mesmos foram mantidos em saliva artificial a $37^{\circ} \mathrm{C}$ em estufa ${ }^{13}$ (Figura 1K) (Torres et al., 2010). A saliva artificial (Figura 2B) foi produzida como descrita por Mcknight-Hanes e Whitford (1992) e modificada por Amaechi et al. (1999).

\section{Composição dos alimentos e bebidas}

A composição dos produtos testados foi fornecida pelo fabricante e o $\mathrm{pH}$ de cada um foi avaliado por meio de um medidor de $\mathrm{pH}$ digital $^{14}$ (Tabela 1 ).

\section{Desafios erosivos e ciclos de imersão}

\section{Ácido clorídrico}

Na tentativa de simular o desafio erosivo (intrínseco) em pacientes portadores de refluxo gastroesofágico, após as medidas de microdureza inicial, cada espécime foi individualmente imerso em $10 \mathrm{ml}$ de solução de ácido clorídrico 0,01 M (Figura 2C) e pH 2 (Hove et al., 2006) por 2 minutos e lavados, em seguida, com água destilada (Amaechi et al., 1999) por aproximadamente 10 segundos.

\section{Alimentos e bebidas}

Após o desafio erosivo dos espécimes com ácido hidroclorídrico e medição da microdureza superficial, cada espécime foi individualmente imerso em lanches (produtos industrializados) por 1 minuto em temperatura ambiente, 2x/dia (9:00 e 15:00 horas), durante 28 dias consecutivos, totalizando 56 ciclos de imersão.

Os produtos teste foram representados por: Leite Achocolatado Toddynho (Pepsico) (Figura 2D) como controle negativo, Suco de Laranja Caseira com Gominhos (del Valle) (Figura 2E) como controle positivo, Papinha de Maçã (Nestlé) (Figura 2F), logurte de Morango (Vigor) (Figura 2G), Leite Fermentado Yakult (Yakult) (Figura 2H) e Petit Suisse Danoninho (Danone) (Figura 2I).

\footnotetext{
${ }^{13}$ Odontobrás Ind. Com. Equip. Med. Odont. LTDA, Brasil

${ }^{14}$ Analion® AN2000, Brasil
} 
Figura 2. Fase experimental
A. Microdurômetro
B. Saliva
C. Ácido clorídrico
D. Leite achocolatado toddynho
E. Suco de laranja
F. Papinha de maçã
G. logurte de morango
H. Leite fermentado yakult
I. Petit suisse danoninho de morango 

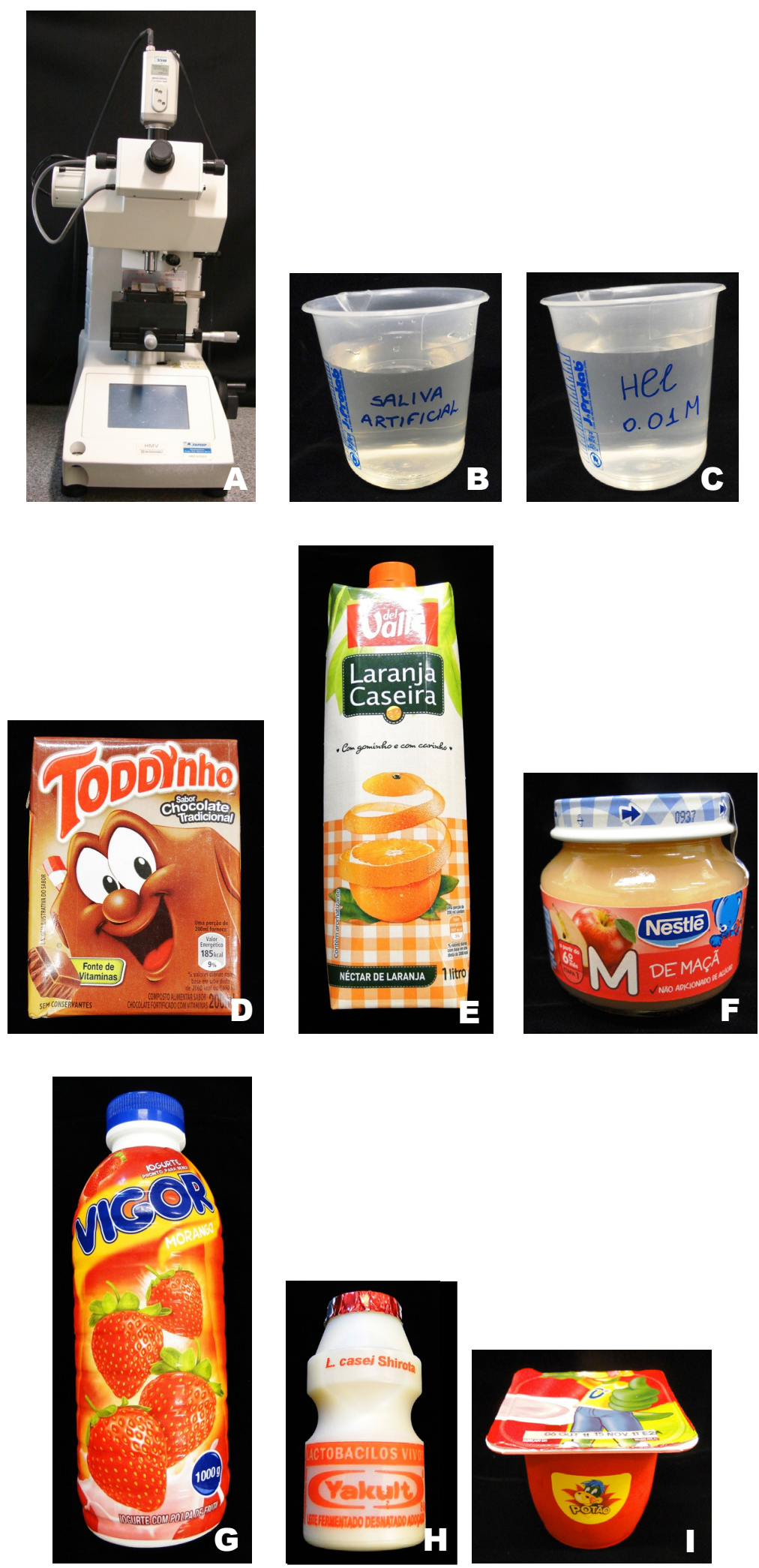

Tabela 1: Descrição da composição dos produtos testados

\begin{tabular}{|c|c|c|}
\hline PRODUTOS & COMPOSIÇÃO* & $\mathrm{pH}^{\star \star}$ \\
\hline $\begin{array}{c}\text { Leite } \\
\text { achocolatado } \\
\text { toddynho }\end{array}$ & $\begin{array}{l}\text { Leite integral reconstituído, açúcar, soro de } \\
\text { leite em pó, cacau, gordura vegetal } \\
\text { hidrogenada, extrato de malte, vitaminas (c, } \\
\text { a e ácido fólico), sal, espessantes: goma } \\
\text { guar e carragena, estabilizantes: mono e } \\
\text { diglicerídeos de ácidos graxos, citrato de } \\
\text { sódio, e lecitina de soja, aromatizante. } \\
\text { Contém glúten. }\end{array}$ & 6,41 \\
\hline $\begin{array}{l}\text { Suco de } \\
\text { laranja }\end{array}$ & $\begin{array}{l}\text { Suco de laranja, água, açúcar, polpa de } \\
\text { laranja, aroma natural, antioxidante, ácido } \\
\text { ascórbico e acidulante ácido cítrico. }\end{array}$ & 3,56 \\
\hline $\begin{array}{l}\text { Papinha de } \\
\text { maçã }\end{array}$ & $\begin{array}{l}\text { Água, maçã, suco de maçã, amido, farinha } \\
\text { de arroz, vitamina c e acidulante ácido } \\
\text { cítrico. }\end{array}$ & 3,78 \\
\hline $\begin{array}{l}\text { logurte de } \\
\text { morango }\end{array}$ & $\begin{array}{l}\text { Leite desnatado, permeado de leite, açúcar, } \\
\text { leitelho, preparado de morango (polpa de } \\
\text { morango, açúcar, água, amido, aroma } \\
\text { artificial de morango, corante natural } \\
\text { carmim de cochonilha, espessante e } \\
\text { estabilizante carragena, acidulante ácido } \\
\text { cítrico e conservante sorbato de potássio), } \\
\text { amido modificado, soro de leite em pó } \\
\text { desnatado e fermento lácteo. Aromatizado } \\
\text { artificialmente. Não contém glúten. }\end{array}$ & 4,19 \\
\hline $\begin{array}{l}\text { Leite } \\
\text { fermentado } \\
\text { yakult }\end{array}$ & $\begin{array}{l}\text { Leite desnatado e/ou leite desnatado } \\
\text { reconstituído, açúcar, glicose, fermento } \\
\text { lácteo e aroma. Não contém glúten. }\end{array}$ & 3,67 \\
\hline $\begin{array}{l}\text { Petit suisse } \\
\text { danoninho }\end{array}$ & $\begin{array}{l}\text { Leite desnatado, xarope de açúcar, } \\
\text { preparado de morango (água, frutose, polpa } \\
\text { de morango, cálcio, fósforo, açúcar, amido } \\
\text { modificado, zinco, ferro, vitaminas D e E, } \\
\text { estabilizantes goma xantana, goma } \\
\text { carragena e carboximetilcelulose, } \\
\text { acidulantes ácido tartárico e ácido cítrico, } \\
\text { aromatizante, conservador sorbato de } \\
\text { potássio e corante natural carmim), creme } \\
\text { de leite, cálcio, cloreto de cálcio, fermento } \\
\text { lácteo, quimosina e estabilizantes goma } \\
\text { guar, carboximetilcelulose, goma carragena } \\
\text { e goma xantana. Contém glúten. Pode } \\
\text { conter traços de castanha de caju. }\end{array}$ & 4,27 \\
\hline
\end{tabular}

${ }^{*}$ De acordo com os respectivos fabricantes.

${ }^{* *}$ Avaliado utilizando-se um medidor de $\mathrm{pH}$ digital. 
Para cada desafio, foram utilizados béqueres padronizados de $20 \mathrm{ml}$ contendo $10 \mathrm{ml}$ dos produtos testes. Em sequência, cada espécime era lavado com água destilada e imerso em $10 \mathrm{ml}$ de saliva artificial por 6 horas (entre os ciclos) e 18 horas (entre o último e o primeiro ciclo do dia seguinte). Após cada ciclo, os produtos testados eram desprezados. A saliva era trocada antes do primeiro ciclo de cada dia.

\section{Microdureza}

Foram realizados seis testes de microdureza: inicial (baseline), após desafio com ácido clorídrico e após 7, 14, 21 e 28 dias de ciclos de imersão com os alimentos e bebidas, utilizando-se um microdurômetro $^{15}$ (Figura 2A), com penetrador piramidal Knoop e carga estática de 25 gf por um período de 30 segundos, no qual foram realizadas três marcações com 100 um de distância entre cada uma.

Os valores de microdureza Knoop em KHN foram registrados pelo software do equipamento ${ }^{16}$ e foram obtidos através do comprimento da maior diagonal das impressões.

Fórmula para transformar a medida das impressões do penetrador em valor de microdureza Knoop:

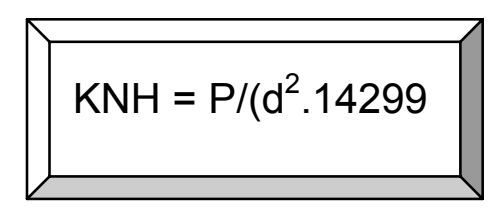
Onde:
$\mathrm{P}=$ carga aplicada durante o teste
$\mathrm{d}=$ maior diagonal da impressão

\section{Microscopia Eletrônica de Varredura}

Foi utilizado um total de 30 dentes, sendo cinco incisivos decíduos de cada produto estudado após os 28 dias de experimento.

\footnotetext{
${ }^{15}$ HMV-2 Shimadzu Japão

${ }^{16}$ HMV-2 Shimadzu, Japão
} 
Ao término do experimento, os espécimes foram preparados para a realização da Microscopia Eletrônica de Varredura (MEV) Zeiss EVO 50. A área dos dentes a ser observada foi marcada utilizando-se ponta diamantada. Em seguida foram lavados abundantemente com água destilada e levados à cuba ultrassônica ${ }^{17}$ para remoção de resíduos. Foram imersos em solução de glutaraldeído $(2,5 \%)$ em tampão cacodilato de sódio $0,1 \mathrm{M}$ e $\mathrm{pH} 7,4$ por um período de 12 horas em temperatura ambiente e lavados com água destilada.

Após fixação e lavagem dos espécimes, os mesmos foram desidratados em graus ascendentes de etanol ${ }^{18}$, sendo a sequência: $25 \%$ (20 minutos), 50\% (20 minutos), $75 \%$ (20 minutos), $95 \%$ (30 minutos) e 100\% (60 minutos). Para finalizar, os espécimes foram imersos em Hexametildissilazano $\left(\mathrm{HMDS}^{19}\right.$ durante 10 minutos, secos com papel absorvente e, então, fixados em stubs. Uma cobertura de ouro foi realizada sobre os espécimes para possibilitar a avaliação em MEV de toda superfície exposta aos produtos. As fotografias foram realizadas com magnitude de 1500 e 5000 vezes.

\section{Análise Estatística}

A Análise de Variância (ANOVA) foi efetuada para delineamento split-plot, no qual foram considerados blocos, tratamentos em seis níveis e medidas repetidas em seis tempos. As comparações entre as variáveis de resposta foram estudadas pela decomposição da soma de quadrados e teste de comparações múltiplas com teste de Tukey em nível de $5 \%$. Os cálculos foram realizados com o auxílio do software STATA $9^{20}$.

$\mathrm{Na}$ Figura 3, pode-se observar a metodologia aplicada ao modelo de estudo proposto, de forma esquematizada.

\footnotetext{
${ }^{17}$ Odontobrás, Brasil

${ }^{18}$ Labsynth Ltda., Brasil

${ }^{19}$ Merck KGaA, Germany

${ }^{20}$ Stata Corp., EUA
} 


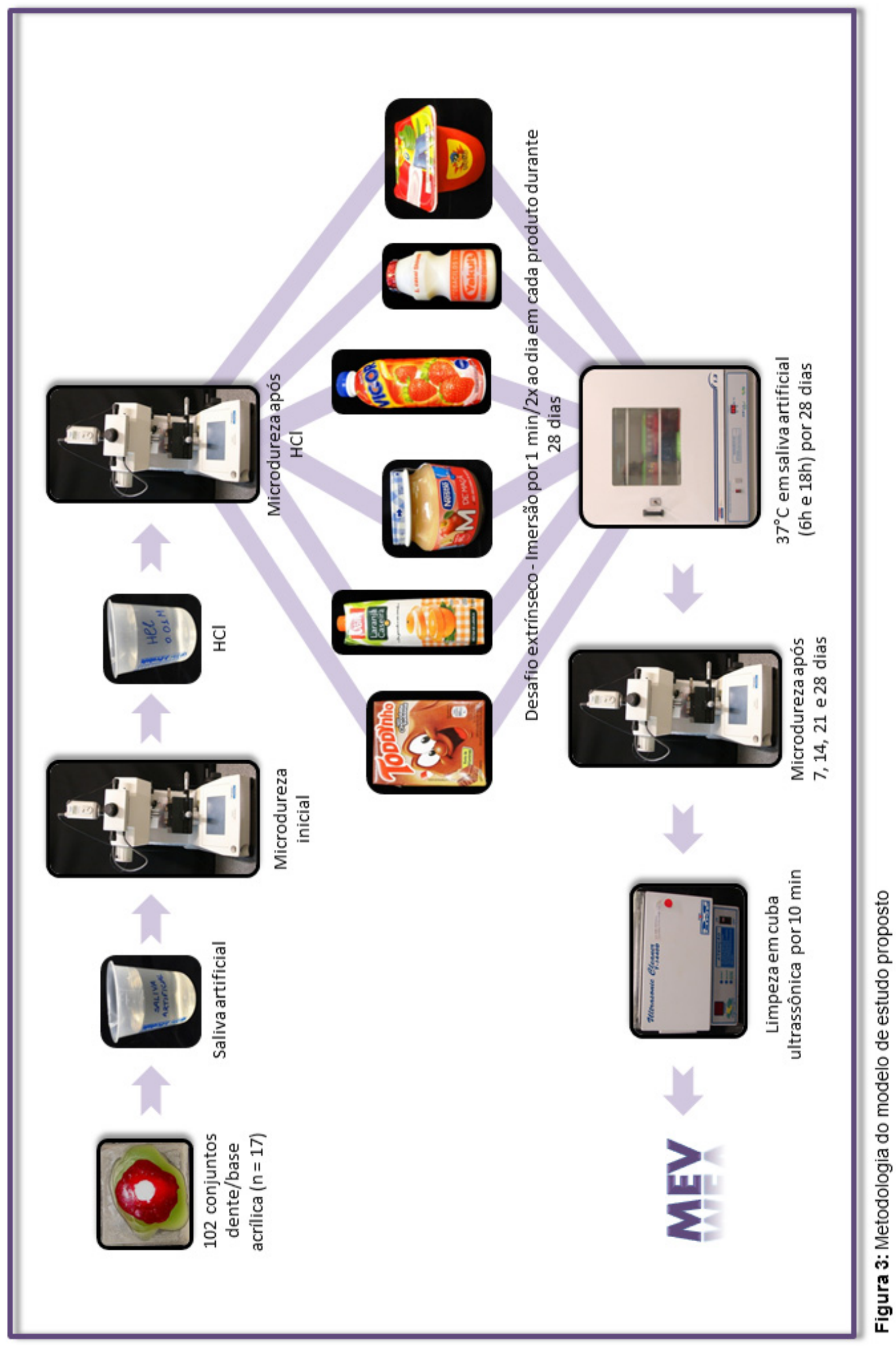



RESULTADOS 


\section{Microdureza Knoop}

A Análise de Variância (ANOVA) a dois critérios, seguida pela soma dos quadrados e pelo teste de Tukey apresentou diferenças significativas para os fatores Lanches ( $p=$ $0.0001)$, Tempo $(p=0.0000)$ e para a interação entre Lanches e Tempo $(p=0.0000)$. Embora os fatores isolados tenham sido significativos, foi analisada a interação por ser mais relevante.

Na tabela abaixo é possível observar as médias dos valores de microdureza Knoop de cada lanche nos diferentes tempos testados.

Tabela 2. Médias e desvios padrão da microdureza Knoop nos diferentes tempos de exposição aos lanches.

Lanches

Tempo

$\begin{array}{ccccc}\begin{array}{c}\text { Inicial } \\ \text { (Baseline) }\end{array} & \mathrm{HCl} & 7 \text { dias } & 14 \text { dias } & 21 \text { dias }\end{array}$

\begin{tabular}{|c|c|c|c|c|c|c|}
\hline $\begin{array}{l}\text { Leite } \\
\text { achocolatado } \\
\text { toddynho }\end{array}$ & $\begin{array}{c}315,12 \\
(49,16)^{\mathrm{Ba}}\end{array}$ & $\begin{array}{c}224,86 \\
(46,65) \text { Aab }\end{array}$ & $\begin{array}{c}237,55 \\
(49,17) \text { Aab }\end{array}$ & $\begin{array}{c}223,77 \\
(46,89)^{\mathrm{Ab}}\end{array}$ & $\begin{array}{c}238,49 \\
(50,62)^{A c}\end{array}$ & $\begin{array}{c}248,92 \\
(51,26)^{\mathrm{Ac}}\end{array}$ \\
\hline $\begin{array}{l}\text { Petit suisse } \\
\text { danoninho de } \\
\text { morango }\end{array}$ & $\begin{array}{c}306,08 \\
(47,26){ }^{\mathrm{Ca}}\end{array}$ & $\begin{array}{c}193,80 \\
(61,94)^{\mathrm{Aa}}\end{array}$ & $\begin{array}{c}233,53 \\
(48,04)^{\mathrm{Bab}}\end{array}$ & $\begin{array}{c}222,05 \\
(55,86){ }^{\mathrm{ABb}}\end{array}$ & $\begin{array}{c}224,68 \\
(52,80)^{A B b c}\end{array}$ & $\begin{array}{c}223,29 \\
(46,80)^{\mathrm{ABbc}}\end{array}$ \\
\hline $\begin{array}{l}\text { logurte de } \\
\text { morango }\end{array}$ & $\begin{array}{c}297,65 \\
(44,72)^{\mathrm{Ba}}\end{array}$ & $\begin{array}{c}232,92 \\
(38,69)^{\mathrm{Ab}}\end{array}$ & $\begin{array}{c}265,55 \\
(57,77))^{\mathrm{ABb}}\end{array}$ & $\begin{array}{c}241,88 \\
(40,25)^{A b}\end{array}$ & $\begin{array}{c}229,65 \\
(36,39)^{A b c}\end{array}$ & $\begin{array}{c}229,25 \\
(51,34)^{A b c}\end{array}$ \\
\hline $\begin{array}{l}\text { Papinha de } \\
\text { maçã }\end{array}$ & $\begin{array}{c}283,53 \\
(56,37)^{\mathrm{Ba}}\end{array}$ & $\begin{array}{c}191,67 \\
(50,20)^{\mathrm{Aa}}\end{array}$ & $\begin{array}{c}223,55 \\
(34,71)^{\mathrm{Aa}}\end{array}$ & $\begin{array}{c}211,23 \\
(48,57)^{\mathrm{Ab}}\end{array}$ & $\begin{array}{c}196,55 \\
(29,22)^{\mathrm{Ab}}\end{array}$ & $\begin{array}{c}200,20 \\
(35,24)^{A b}\end{array}$ \\
\hline $\begin{array}{l}\text { Suco de } \\
\text { laranja }\end{array}$ & $\begin{array}{c}318,84 \\
(59,22) \mathrm{Ca}\end{array}$ & $\begin{array}{c}222,88 \\
(60,15){ }^{\text {Bab }}\end{array}$ & $\begin{array}{c}199,33 \\
(36,60)^{\mathrm{Ba}}\end{array}$ & $\begin{array}{c}148,72 \\
(36,89)^{\mathrm{Aa}}\end{array}$ & $\begin{array}{c}148,98 \\
(42,20)^{\mathrm{Aa}}\end{array}$ & $\begin{array}{c}132,45 \\
(39,83)^{\mathrm{Aa}}\end{array}$ \\
\hline $\begin{array}{l}\text { Leite } \\
\text { fermentado } \\
\text { yakult }\end{array}$ & $\begin{array}{c}292,49 \\
(61,73)^{\mathrm{Ba}}\end{array}$ & $\begin{array}{c}191,47 \\
(59,45)^{\mathrm{Aa}}\end{array}$ & $\begin{array}{c}214,51 \\
(52,53)\end{array}$ & $\begin{array}{c}213,51 \\
(49,21)^{A b}\end{array}$ & $\begin{array}{c}219,10 \\
(51,18) \text { Abc }\end{array}$ & $\begin{array}{c}221,10 \\
(49,27)\end{array}$ \\
\hline
\end{tabular}

Letras maiúsculas sobrescritas indicam análise em linhas e letras minúsculas, análise em colunas.

Letras diferentes indicam diferença estatística $(p \leq 0,05)$. 
Ao se observar o fator tempo (em linhas), nota-se que houve diminuição nos valores de microdureza superficial do esmalte dental decíduo após simulação de desafio erosivo endógeno com ácido clorídrico em comparação aos valores médios iniciais.

Leite achocolatado toddynho, papinha de maçã e leite fermentado yakult, apresentaram diminuição significativa entre os valores de microdureza inicial e ao longo de 7, 14, 21 e 28 dias, não havendo diferença significativa entre eles e o desafio erosivo em ácido clorídrico.

Após 14 dias de exposição ao petit suisse danoninho e ao iogurte de morango, os espécimes tiveram a microdureza superficial do esmalte diminuída, porém não foi significativamente diferente da exposição ao ácido clorídrico e do sétimo dia de experimento. No sétimo dia de imersão em iogurte de morango, o valor médio de microdureza aumentou em relação ao desafio erosivo com ácido clorídrico, no entanto, apesar de apresentar valor médio inferior ao baseline não foi significativamente diferente deste.

O suco de laranja, embora após o desafio erosivo com ácido clorídrico tenha apresentado valor diminuído de microdureza ao sétimo dia, não apresentou diferença estatística significativa, contudo, após 14 dias, houve uma diminuição significativa nos valores de microdureza do esmalte. Com 14, 21 e 28 dias não houve diferença estatística entre eles.

Comparando-se, em colunas, os valores de microdureza do esmalte no tempo inicial (baseline), nota-se que não houve diferença estatística entre os lanches. Ao expor os espécimes ao ácido clorídrico, ocorreu uma diminuição nos valores médios de microdureza superficial do esmalte dental decíduo, porém os espécimes representados pelo iogurte diferiram estatisticamente dos representados pelo petit suisse danoninho, papinha e leite fermentado yakult, que não diferiram entre si. Não houve diferença estatística entre os valores médios dos espécimes representados pelo leite achocolatado toddynho, petit suisse danoninho, papinha, suco de laranja e leite fermentado yakult, nem entre os representados pelo leite achocolatado toddynho, iogurte e suco de laranja.

No sétimo dia de exposição aos lanches, o iogurte de morango apresentou valor médio de microdureza significativamente maior do que a papinha, suco de laranja e leite fermentado yakult, entretanto não diferiu estatisticamente do petit suisse danoninho e leite achocolatado toddynho, que também não diferiram entre si. 
Após 14 dias, houve uma diminuição geral dos valores de microdureza superficial do esmalte, porém apenas o suco de laranja apresentou diferença estatística significante.

Aos 21 e 28 dias, o suco de laranja apresentou valor médio significativamente menor do que todos os lanches. O leite achocolatado toddynho apresentou valor médio significativamente maior do que a papinha e o suco de laranja, mas não foi significativamente maior do que o petit suisse danoninho, iogurte de morango e leite fermentado yakult.

A figura 4 ilustra estes resultados.

Microdureza Superficial (Knoop) x Tempo

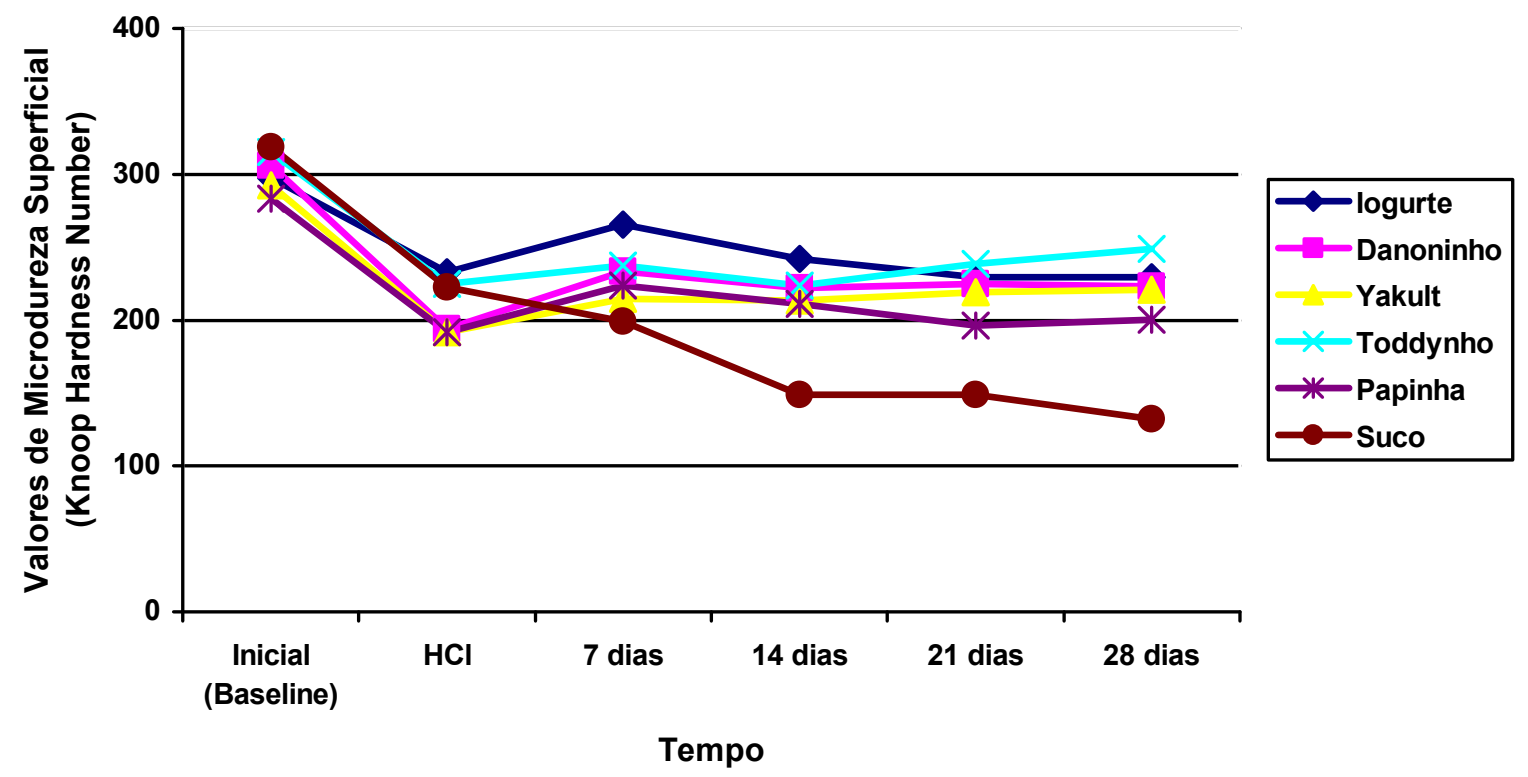

Figura 4. Valores médios de microdureza Knoop superficial de cada lanche em função do tempo. 


\section{Microscopia Eletrônica de Varredura}

A avaliação qualitativa por Microscopia Eletrônica de Varredura (MEV) da superfície do esmalte foi realizada em 30 dentes (cinco de cada produto teste) ao término dos 28 dias de experimento. As imagens dos espécimes foram realizadas com aumentos de 1500 e 5000 vezes.

Os padrões morfológicos das superfícies avaliadas foram determinados de acordo com o padrão de desmineralização do esmalte classificados por Silverstone et al. (1975). Nos grupos submetidos à exposição com leite achocolatado toddynho (controle negativo), papinha de maçã e suco de laranja (controle positivo), o padrão de desmineralização predominante foi tipo I, com destruição do centro dos prismas de esmalte e preservação da periferia (Figuras 5, 6 e 7). Em contrapartida, nos espécimes expostos ao iogurte de morango, petit suisse danoninho de morango e leite fermentado yakult, observou-se padrão tipo II, com remoção da periferia dos prismas de esmalte e preservação da porção central (Figuras 8, 9 e 10). 
46 Resultados 


\section{Leite Achocolatado Toddynho}
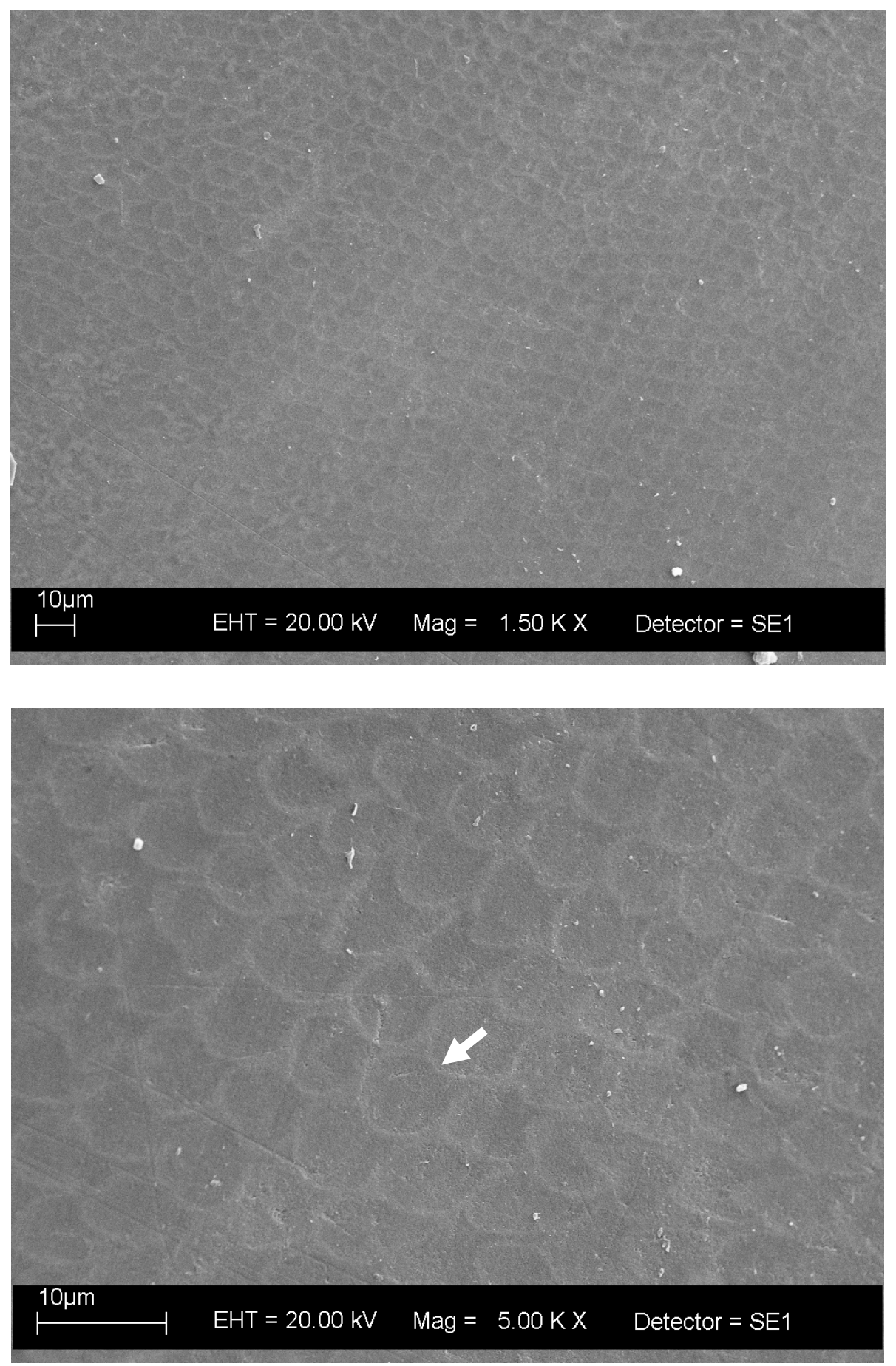

Figura 5. Superfície de esmalte dental decíduo com desmineralização principalmente no centro dos prismas do esmalte semelhante ao padrão tipo I de Silverstone et al. (1975). 
48 Resultados 


\section{Papinha de maçã}
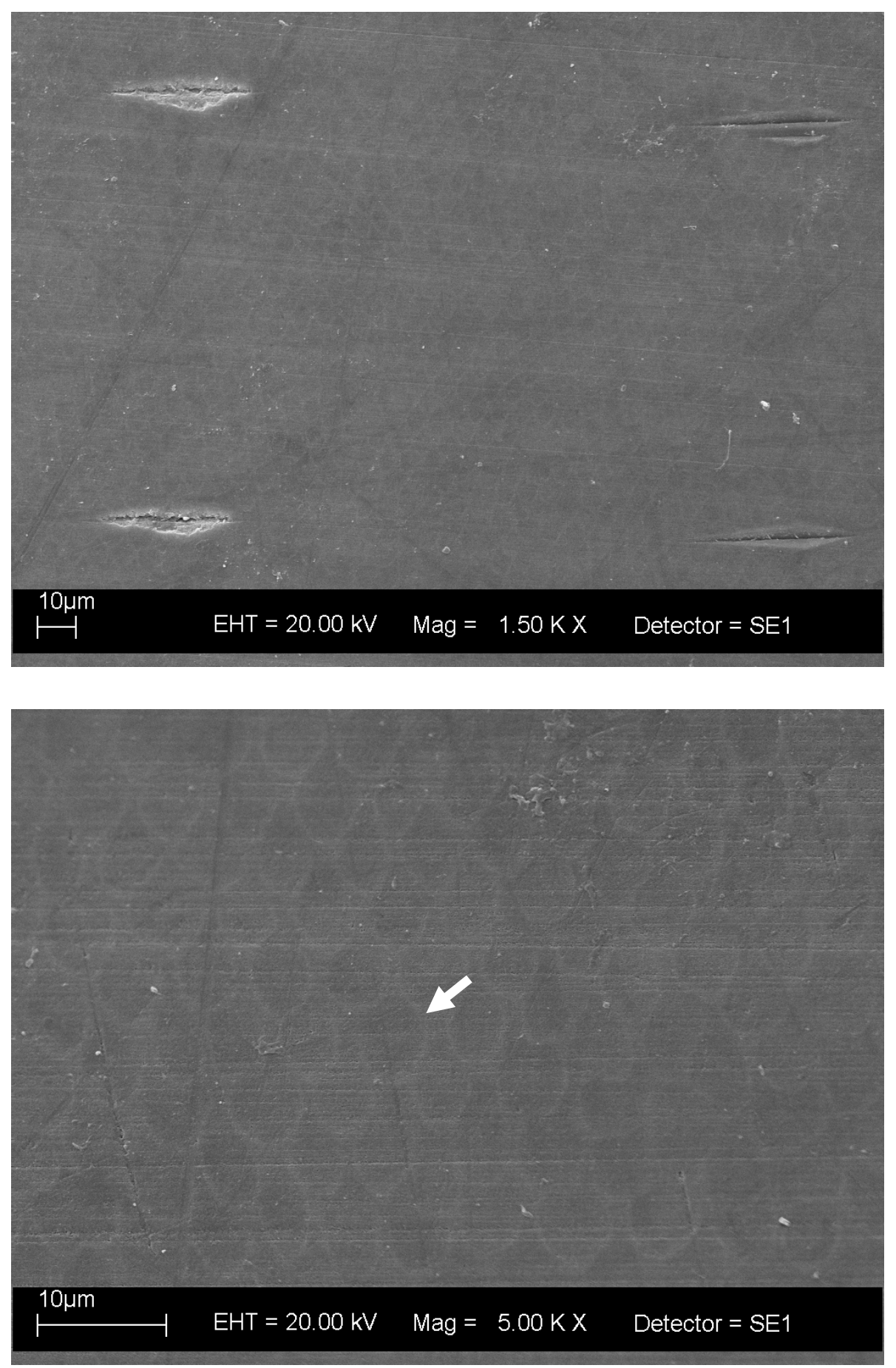

Figura 6. Superfície de esmalte dental decíduo com desmineralização principalmente no centro dos prismas do esmalte semelhante ao padrão tipo I de Silverstone et al. (1975). 
50 Resultados 


\section{Suco de laranja}
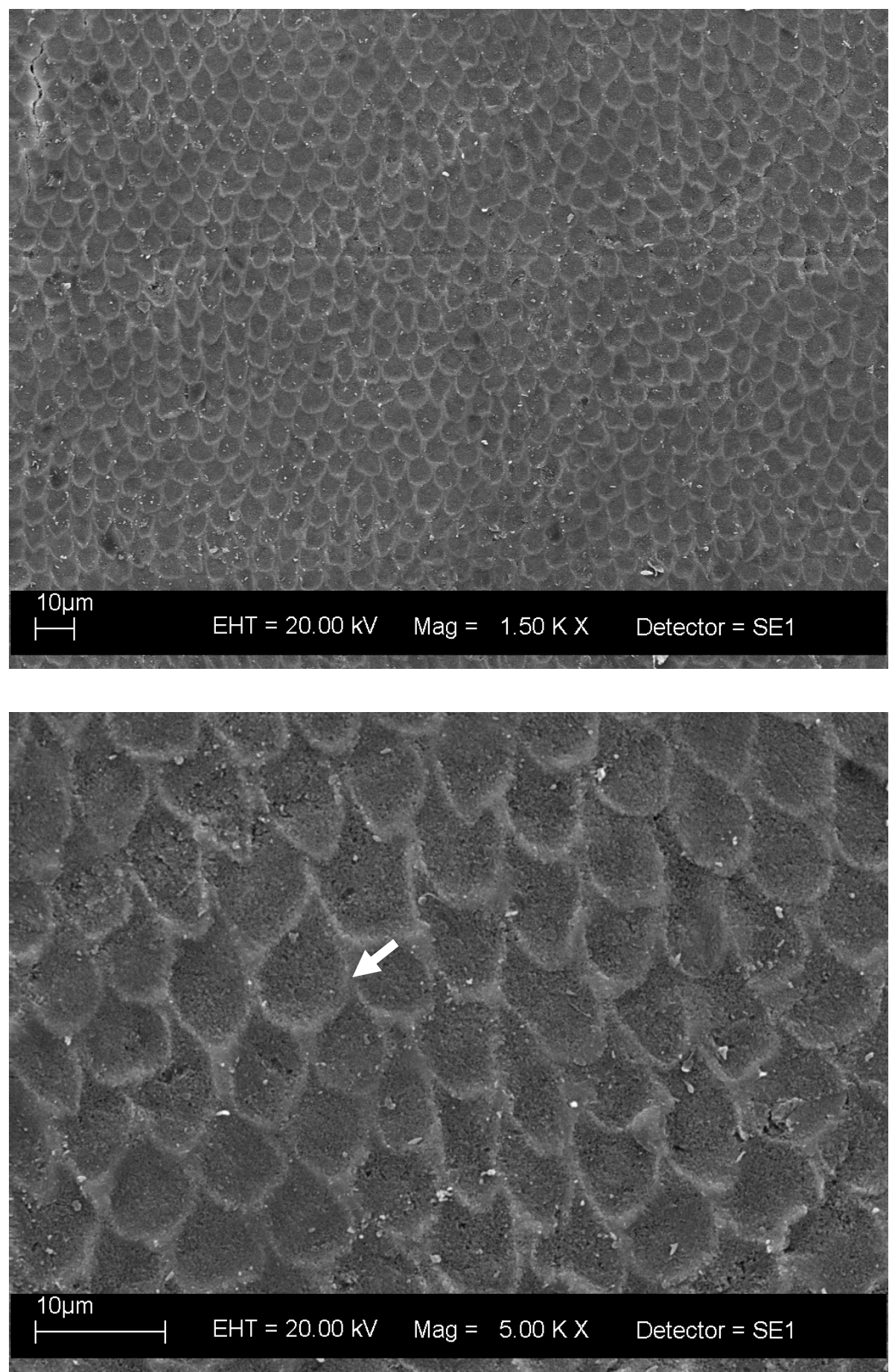

Figura 7. Superfície de esmalte dental decíduo com desmineralização principalmente no centro dos prismas do esmalte semelhante ao padrão tipo I de Silverstone et al. (1975). 


\section{logurte de morango}
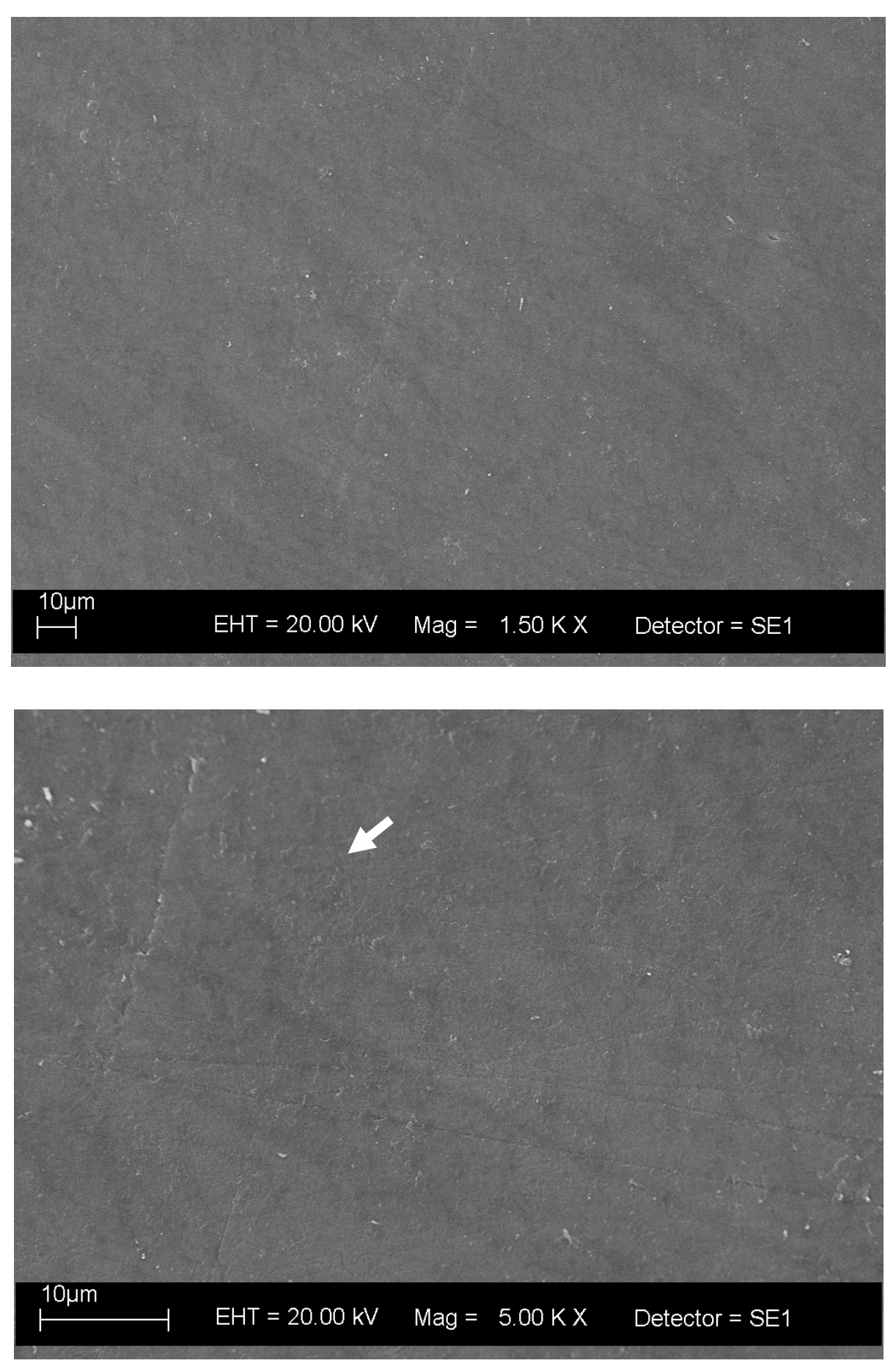

Figura 8. Superfície de esmalte dental decíduo com desmineralização principalmente na periferia dos prismas do esmalte semelhante ao padrão tipo II de Silverstone et al. (1975). 


\section{Leite Fermentado Yakult}
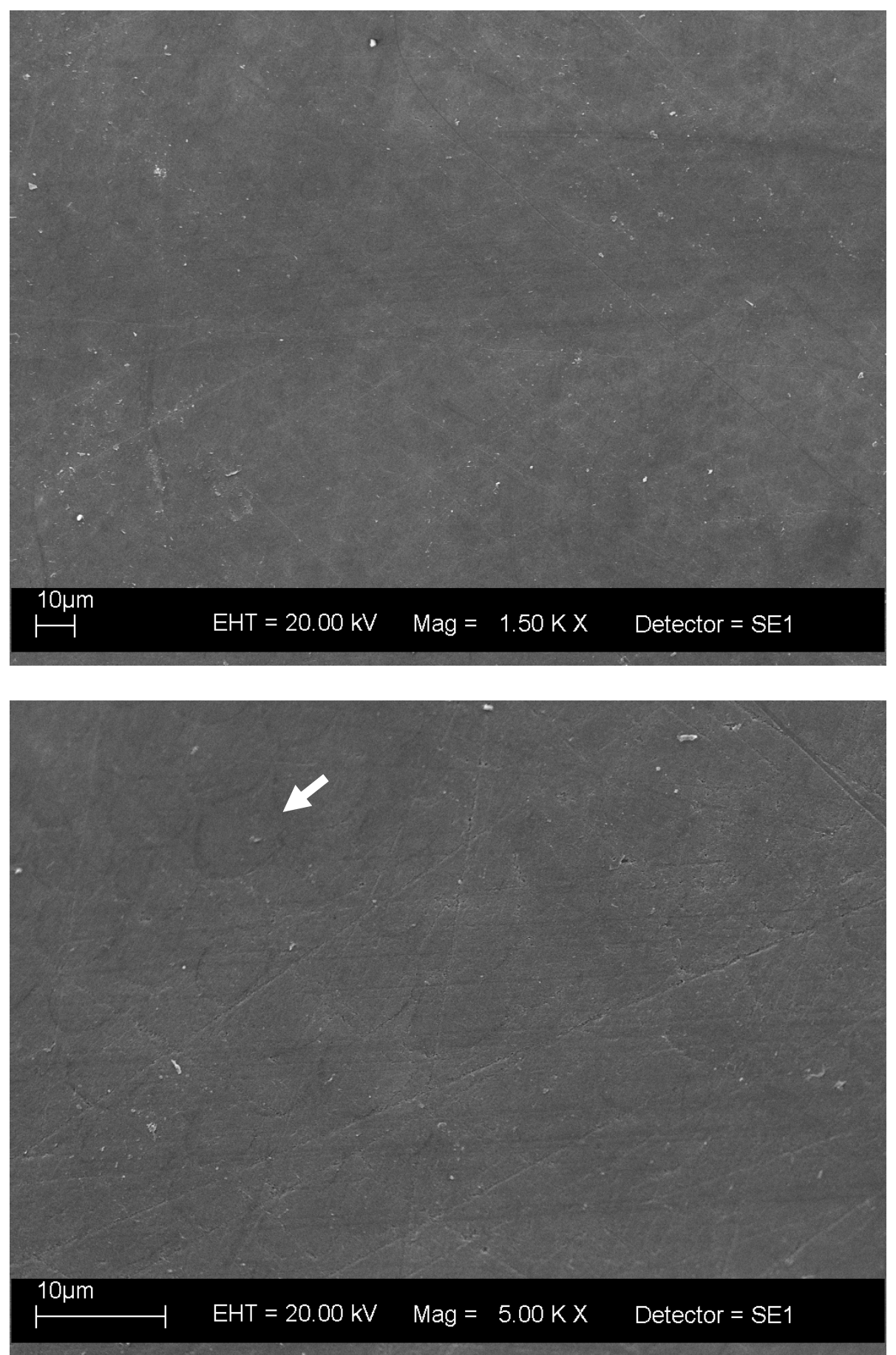

Figura 9. Superfície de esmalte dental decíduo com desmineralização principalmente na periferia dos prismas do esmalte semelhante ao padrão tipo II de Silverstone et al. (1975). 
56 Resultados 


\section{Petit Suisse Danoninho de morango}
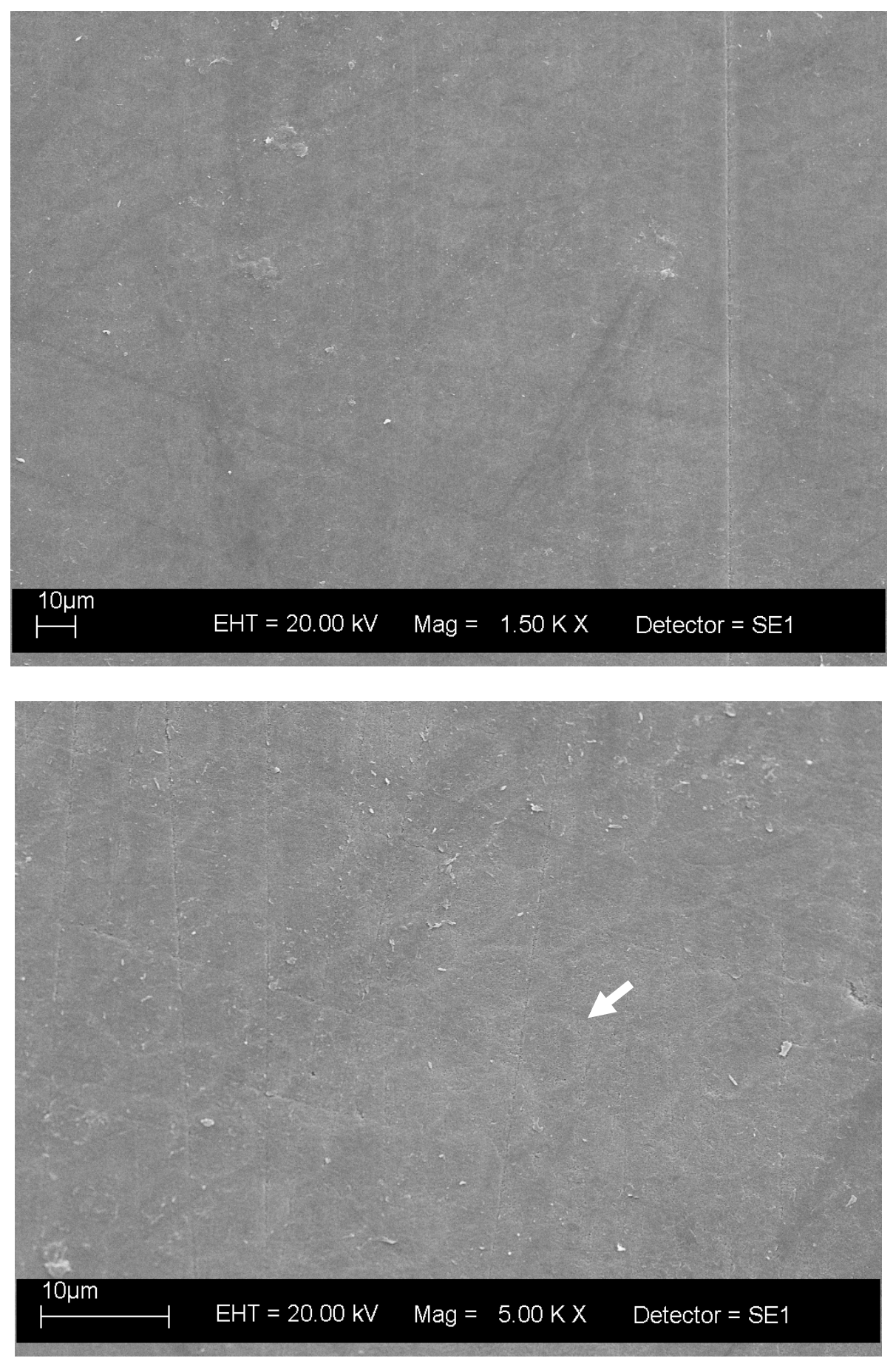

Figura 10. Superfície de esmalte dental decíduo com desmineralização principalmente na periferia dos prismas do esmalte semelhante ao padrão tipo II de Silverstone et al. (1975). 

DISCUSSÃO 
Mudanças na dieta e estilo de vida têm ocorrido com a industrialização, urbanização, desenvolvimento econômico e globalização, causando impacto na saúde, principalmente nos países desenvolvidos e em desenvolvimento (WHO, 2003). Embora exista praticidade, durabilidade e aceitação dos alimentos e bebidas industrializados (Aquino e Philippi, 2002), muitas vezes, o conteúdo ácido presente na dieta tem favorecido o surgimento de lesões de desgaste, como a erosão dental (Lussi e Jaeggi, 2006). Além da dieta ácida, a erosão também é ocasionada pelo contato frequente com o ácido clorídrico na cavidade bucal (Bartlett, 2006; Hove et al., 2006), sendo uma condição comum em pacientes pediátricos com refluxo gastresofágico (Alfaro et al., 2008).

O ácido gástrico tem $\mathrm{pH}$ entre 0,9-1,5 porém, na cavidade bucal, o pH após vômitos raramente é inferior a 1,5, devido ao efeito tampão e diluição (Hove et al., 2006). Neste estudo, optou-se por simular um episódio de refluxo gastroesofágico. O protocolo proposto foi adaptado do modelo in vitro de Hove et al. (2006), no qual simularam três episódios de refluxo gastroesofágico utilizando ácido clorídrico a $0,01 \mathrm{M} \mathrm{e} \mathrm{pH} \mathrm{2,} \mathrm{por} \mathrm{ser} \mathrm{clinicamente} \mathrm{mais}$ relevante (Hove et al., 2006). Considerando-se que uma única exposição ao ácido seja suficiente para observar a perda parcial de minerais na superfície do dente (Shellis et al., 2011), a simulação de desafio erosivo intrínseco foi realizada uma única vez em $10 \mathrm{ml}$ de ácido clorídrico, numa área de $2 \mathrm{~mm}$ de diâmetro, por 2 minutos, na tentativa de provocar uma lesão inicial de erosão dental. O ácido clorídrico, mais apropriado para realização de modelos de erosão intrínseca (Young e Tenuta, 2011), é um ácido forte (West et al., 2001) e, na presença de água, dissocia-se completamente em íons hidrogênio e cloreto, dissolvendo e removendo a superfície mineral (Featherstone e Lussi, 2006). As exposições ácidas de curta duração provocam alterações superficiais antes de se observar perda de estrutura dentária (Young e Tenuta, 2011). Desejando-se imitar as condições bucais in vivo, os espécimes foram pré-tratados em saliva artificial antes das medidas iniciais de microdureza superficial do esmalte, como proposto por Shellis et al., 2011. Embora tenha existido padronização da metodologia aplicada na escolha do substrato (dentes decíduos), tamanho dos espécimes, medidas iniciais de microdureza (baseline), pré-tratamento com saliva artificial, volume e tempo de exposição ao ácido, neste estudo, houve diferença 
estatística entre os grupos expostos ao ácido clorídrico, limitando a comparação de lanches dentro de cada tempo.

Supondo-se que a dieta poderia interferir no processo de desmineralização e remineralização da superfície do esmalte dental já causado pelo desafio erosivo intrínseco, foram utilizados alimentos e bebidas industrializados, comumente oferecidos às crianças como lanche. Todos os produtos selecionados, com exceção do leite achocolatado toddynho (pH 6,41), apresentam pH abaixo do pH crítico para dissolução da hidroxiapatita, que é em torno de 5,5 (Thystrup e Fejerskov, 2001). Embora Ferreira e Pozzobon (2009) afirmem que o $\mathrm{pH}$ de produtos à base de chocolate não teriam potencial para causar erosão dental, não existem trabalhos na literatura que testem especificamente seu efeito remineralizante. Produtos à base de leite podem ter efeito protetor e não causar desmineralização do esmalte, dependendo da quantidade de cálcio e fosfato (Rytömaa et al., 1988). O leite bovino mostrou-se capaz de provocar remineralização da superfície de esmalte dental bovino após desafio erosivo com água clorada (Vongsawan et al., 2010). O leite achocolatado toddynho possui cálcio em sua composição e foi escolhido como controle negativo na expectativa que remineralizasse a superfície dental previamente exposta ao ácido clorídrico. Os resultados deste experimento mostraram que, embora não tenha remineralizado a superfície do esmalte dental decíduo ao longo dos 28 dias de experimento, o leite achocolatado testado (toddynho) também não agravou o efeito erosivo do ácido clorídrico, mesmo contendo ácido fólico e vitamina $\mathrm{C}$ em sua composição.

O suco de laranja foi escolhido como controle positivo devido ao seu reconhecido potencial erosivo (Hunter et al., 2009), pela presença de ácido cítrico (Rugg-Gunn et al., 1998). No entanto, o potencial erosivo de uma bebida ácida é influenciado não só pelo tipo do ácido (Grenby, 1996; Lussi et al., 2004), mas também pela sua capacidade tampão, propriedade quelante, frequência e duração da ingestão (Lussi, 1996). O efeito erosivo do suco de laranja foi observado em estudos anteriores (Rytömaa et al., 1988; Larsen e Nyvad, 1999; Lussi et al., 2000; Lussi e Hellwig, 2001; Wongkhantee et al., 2006; Jitpukdeebodintra et al., 2010; Torres et al., 2010) por diferentes protocolos em relação ao volume, tempo de exposição, duração do desafio erosivo e interposição com saliva. No entanto, nenhum 
trabalho avaliou o efeito do suco de laranja ou outros alimentos e bebidas após simulação de desafio erosivo endógeno em dentes decíduos, como no presente estudo. Embora Torres et al. (2010) tenham avaliado o efeito erosivo do suco de laranja sobre o esmalte dental decíduo e observado perda mineral na superfície após 45 dias, no presente estudo, a microdureza superficial do esmalte diminuiu após 14 dias e se manteve constante aos 21 e 28 dias de experimento. Talvez, a diminuição da microdureza do esmalte em menor tempo de exposição se justifique pelo fato do suco de laranja $(\mathrm{pH} \mathrm{3,56)}$ utilizado neste trabalho, ser puro, enquanto que o suco de laranja utilizado por Torres et al. (2010) seja à base de soja $(\mathrm{pH} 3,86)$. Outra possível explicação seria o efeito cumulativo do desafio erosivo prévio com ácido clorídrico, seguido de exposição ao suco de laranja, que apresenta ácido cítrico e, embora seja um ácido fraco, tem propriedade de quelar cálcio da hidroxiapatita (Amaechi et al., 1999) e promover dissolução dos cristais pela ligação de íons hidrogênio ao carbonato e/ou fosfato (Featherstone e Lussi, 2006).

Os lanches petit suisse danoninho de morango, iogurte de morango e papinha de maçã foram selecionados também por apresentarem acidulante ácido cítrico em suas composições. Apesar do fabricante não mencionar a presença de acidulante ácido cítrico ou outros ácidos, o leite fermentado (yakult) tem pH ácido, de 3,67, e foi capaz de provocar perda mineral superficial em esmalte dental bovino após um total de 20 minutos de exposição, intercalando-se com saliva artificial (Lodi et al., 2010). Neste estudo, ao final dos 28 dias de experimento e um total de 56 minutos de exposição, o leite fermentado yakult não potencializou a perda mineral causada pela simulação de desafio endógeno. Uma possível explicação, para esta diferença de resultados, estaria na realização de um desafio erosivo maior no trabalho de Lodi et al. (2010), que avaliaram desgaste da superfície de esmalte dental por perfilometria. Embora não existam trabalhos que tenham testado o potencial ou efeito erosivo da papinha de maçã, esperava-se diminuição da microdureza superficial do esmalte, não só pelo seu pH ácido, que é de 3,58, mas também pelos achados de Lussi e Jaeggi (2001) após expor dentes permanentes ao purê de maçã. Neste trabalho, mesmo após um total de 56 minutos de exposição, a papinha não agravou a perda mineral causada pelo desafio erosivo com ácido clorídrico. No entanto, deve-se considerar que foram realizadas duas exposições diárias à papinha de maçã por 1 minuto, intercaladas com saliva 
por aproximadamente 24 horas, diferente do estudo de Lussi e Jaeggi (2001), com apenas uma exposição ao purê de maçã, por 10 ou 20 minutos, sem interposição salivar. Também não existem trabalhos avaliando o petit suisse danoninho de morango, impossibilitando comparações. Apesar do petit suisse danoninho ter aumentado a microdureza do esmalte no sétimo dia de desafio, não diferenciou do ácido clorídrico após 14 dias de exposição. Embora contenha dois ácidos (cítrico e tartárico) e pH abaixo de 7, o petit suisse danoninho apresenta cálcio e fósforo em sua composição. Estudos apontam que o iogurte apresenta alta concentração de cálcio e não teria potencial (Lussi et al., 2000; Caglar et al., 2006;

Kargul et al., 2007) ou efeito (Lussi et al., 2004; Caglar et al., 2005; Wongkhantee et al., 2005; Waterhouse et al., 2008; Lussi et al., 2011) erosivo sobre o esmalte dental. Porém, em estudo recente (Jitpukdeebodintra et al., 2010), o iogurte reduziu a microdureza do esmalte dental permanente após desafios prévios com suco de laranja e interposição de saliva artificial. No presente modelo experimental, o iogurte de morango $(\mathrm{pH} \mathrm{4,19)}$ não reduziu a microdureza do esmalte dental decíduo. Além da diferença entre o tipo de ácido utilizado nos desafios prévios, também houve diferença no tipo de desafio. No experimento de Jitpukdeebodintra et al. (2010) o suco de laranja foi intercalado com iogurte por 60 dias, totalizando 120 minutos de exposição ao suco de laranja e 600 minutos em iogurte, enquanto neste protocolo adotado foi utilizada uma única exposição ao ácido clorídrico e várias exposições aos produtos testes, intercalados por saliva artificial.

$\mathrm{Na}$ tentativa de simular os períodos de lanche das crianças em escola, o protocolo proposto foi realizado expondo-se os espécimes, inicialmente ao ácido clorídrico por 2 minutos e umidade relativa à $37^{\circ} \mathrm{C}$ por 24 horas e aos produtos teste, $2 x /$ dia por 1 minuto, intercalando-se com saliva artificial. A saliva utilizada foi descrita por McKnight-Hanes e Whitford (1992) e modificada por Amaechi et al. (1999), a qual possui cálcio, fosfato e magnésio em sua composição e efeito remineralizante semelhante à saliva humana fresca (Amaechi e Higham, 2001; Torres et al., 2010). Considerando-se o tempo de exposição, a opção por 2 minutos em ácido clorídrico e 1 minuto nos produtos teste foi baseada em reproduzir melhor as condições bucais, visto que não se deve ultrapassar 2 min (Young e Tenuta, 2011). As lesões iniciais de erosão podem ser provocadas tanto por modelos de curta exposição ao ácido (Young e Tenuta, 2011), como na simulação de desafio endógeno, 
quanto por curtos ciclos de exposição ao ácido, seguida de imersão em saliva (Young e Tenuta, 2011), como nas exposições aos produtos teste por 1 minuto. A duração de ensaios, in vitro, pode variar entre $15 \mathrm{~s}$ e $40 \mathrm{~min}$ por ciclo (Wiegand e Attin, 2011), dependendo do estágio de lesão que se quer obter. A erosão do esmalte é inicialmente manifestada por desmineralização parcial da superfície devido ao elevado conteúdo mineral (Schlueter et al., 2011), assim, neste estudo, optou-se por realizar medidas de microdureza superficial do esmalte, por ser a técnica de avaliação mais utilizada para medir o amolecimento da superfície dental (Shellis et al., 2011). A microdureza superficial do esmalte é um método quantitativo simples, de baixo custo e facilmente realizado (Barbour e Rees, 2004) pela medição da resistência de um substrato à penetração de um indentador, que pode ser Vickers (tetra-piramidal) ou Knoop (romboidal) (Schlueter et al., 2011). A microdureza superficial Knoop foi escolhida, neste experimento, por ser considerada mais sensível às alterações da camada mais superficial de uma lesão erosiva (Schlueter et al., 2011).

Nos resultados obtidos pelas medidas de microdureza Knoop, observou-se que após simulação de desafio endógeno com ácido clorídrico, nenhum dos lanches utilizados foi capaz de recuperar a microdureza do esmalte dental decíduo ao longo do tempo final de exposição (28 dias), enquanto o suco de laranja foi o produto que resultou em maior perda mineral do esmalte. As alterações morfológicas do tecido dental também foram ilustradas por Microscopia Eletrônica de Varredura (MEV). A MEV é uma técnica qualitativa (Schlueter et al., 2011), na qual se pode observar e classificar os padrões morfológicos das superfícies. No presente experimento, de acordo com o padrão de desmineralização do esmalte classificados por Silverstone et al. (1975), leite achocolatado toddynho (controle negativo), papinha de maçã e suco de laranja (controle positivo) revelaram padrão de desmineralização tipo I, com destruição do centro dos prismas de esmalte e preservação da periferia e, nos espécimes expostos ao iogurte de morango, petit suisse danoninho de morango e leite fermentado yakult, observou-se padrão de desmineralização tipo II, com remoção da periferia dos prismas de esmalte e preservação da porção central. No entanto, apesar dos padrões morfológicos verificados, o padrão de condicionamento ácido pode variar significativamente, em indivíduos diferentes, de dente para dente e entre diferentes 
áreas do mesmo dente (Jörgensen, 1975). Assim, comparações entre os grupos são dificultadas, uma vez que, apenas porções simétricas de dentes contralaterais, no mesmo indivíduo, apresentam padrões de desmineralização semelhantes (Jörgensen, 1975).

Embora este modelo experimental tenha sido realizado na tentativa de simular uma condição bucal in vivo, sabe-se que estudos laboratoriais, importantes para contribuições científicas futuras, têm limitações e não devem ser conclusivos para as situações clínicas. São necessários mais estudos para fundamentar conclusões definitivas sobre o potencial e efeito erosivo do leite achocolatado toddynho, petit suisse danoninho de morango, iogurte de morango, papinha de maçã e leite fermentado yakult. Entretanto, principalmente em pacientes com refluxo gastroesofágico, cuidados com a dieta ácida devem ser tomados, visto que o $\mathrm{pH}$ ácido e o conteúdo de alimentos e bebidas, podem favorecer a instalação de lesões de erosão dental, como provocado pelo suco de laranja neste estudo. 

CONCLUSÃO 
Diante dos resultados encontrados neste estudo, pode-se concluir que:

- O leite achocolatado toddynho, utilizado como controle negativo, não foi capaz de remineralizar a superfície do esmalte dental decíduo, após o desafio erosivo com ácido clorídrico.

- Os lanches iogurte, petit suisse danoninho de morango, leite fermentado yakult e papinha de maçã não induziram remineralização, nem desmineralização do esmalte dental decíduo exposto anteriormente ao ácido clorídrico.

- O suco de laranja, utilizado como controle positivo, potencializou o desgaste dental provocado pelo ácido clorídrico ao longo dos 28 dias de experimento.

- Leite achocolatado toddynho, papinha de maçã e suco de laranja apresentaram padrão de desmineralização tipo I de Silverstone, com destruição do centro dos prismas de esmalte e preservação da periferia.

- logurte de morango, petit suisse danoninho de morango e leite fermentado yakult apresentaram padrão de desmineralização tipo II de Silverstone, com remoção da periferia dos prismas de esmalte e preservação da porção central. 
REFERENCIAS 
1. Addy M, Shellis RP. Interaction between attrition, abrasion and erosion in tooth wear. Dental erosion: from diagnosis to therapy. Monographs in oral science 2006;20:9-16.

2. Alfaro EV, Aps JK, Martens LC. Oral implications in children with gastroesophageal reflux disease. Current Opinion in Pediatrics 2008, 20:576-583.

3. Amaechi BT, Higham SM, Edgar WM. Efficacy of sterilisation methods and their effect on enamel demineralisation. Caries Res 1998;32:441-46.

4. Amaechi BT, Higham SM, Edgar WM. Factors influencing the development of dental erosion in vitro: enamel type, temperature and exposure time. J Oral Rehabil 1999;26(8):624-30.

5. Amaechi BT, Higham SM. In vitro remineralisation of eroded enamel lesions by saliva. Journal of Dentistry 2001;29:371-76.

6. Amaechi BT, Higham SM. Dental erosion: possible approaches to prevention and control. Journal of Dentistry 2005; 33:243-52.

7. Aquino RC, Philippi ST. Consumo infantil de alimentos industrializados e renda familiar na cidade de São Paulo. Rev Saúde Pública 2002;36(6):655-60.

8. Barbour ME, Rees JS. The laboratory assessment of enamel erosion: a review. Journal of Dentistry 2004;32:591-602. 
9. Bartlett DW, Evans DF, Smith BGN. The relationship between gastro-oesophageal reflux disease and dental erosion. Journal of Oral Rehabilitation 1996; 23:289-97.

10. Bartlett D. Intrinsec causes of erosion. Monogr Oral Sci. Basel, Karger, 2006, 20:119_ 39.

11. Caglar E, Kargul B, Tanboga I, Lussi A. Dental erosion among children in an Istanbul Public School. JDC 2005; 721-26.

12. Caglar E, Lussi A, Kargul B, Kabalay U. Fruit yogurt: any erosive potential regardig teeth?. Quintessence Int 2006;37:647-51.

13. Davies AEM, Sandhu BK. Diagnosis and treatment of gastro-oesophageal reflux. Archives of Disease in Childhood 1995; 73: 82-86.

14. Featherstone JD, Lussi A. Understanding the chemistry of dental erosion. Monogr Oral Sci. 2006;20:66-76.

15. Ferreira FV, Pozzobon RT. Processed dairy beverages $\mathrm{pH}$ evaluation: consequences of temperature variation. J Clin Pediatr Dent 2009;33(4):319-24.

16. Grenby TH. Lessening dental erosive potential by product modification. Eur J Oral Sci 1996; 104: 221-228.

17. Haukioja A. Probiotics and Oral Health. Eur J Dent 2010;4:348-55.

18. Hove LH, Holme B, Øgaard B, Willumsen T, Tveit AB. The protective effect of $\mathrm{TiF}_{4}$, $\mathrm{SnF}_{2}$ and $\mathrm{NaF}$ on erosion of enamel by hydrochloric acid in vitro measured by white light interferometry. Caries Res 2006;40:440-43. 
19. Hunter L, Patel S, Rees J. The in vitro erosive potential of a range of baby drinks. International Journal of Paediatric Dentistry 2009; 19:325-29.

20. Hurley KM, Black MM. Commercial baby food consumption and dietary variety in statewide sample in infants receiving benefits from the special supplemental nutrition program for women, infants, and children. J Am Diet Assoc 2010; 110:1537-41.

21. Imdad A, Yakoob MY, Bhutta ZA. Impact of maternal education about complementary feeding and provision of complementary foods on child growth in developing countries. Public Health 2011; 11(Suppl 3):S25.

22. Järvinen VK, Rytömaa II, Heinonen OP. Risk factors in dental erosion. J Dent Res 1991; 70(6):942-47.

23. Jitpukdeebodintra S, Chuenarrom C, Muttarak C, Khonsuphap P, Prasattakarn S. Effects of $1.23 \%$ acidulated phosphate fluoride gel and drinkable yogurt on human enamel erosion, in vitro. Quintessence Int 2010;41:595-604.

24. Jörgensen KD. Contralateral symmetry of acid etched enamel surfaces. Scand. J. Dent. Res. 1975: 83: 26-30.

25. Kargul B, Caglar E, Lussi A. Erosive and buffering capacities of yogurt. Quintessence Int 2007;38:381-85.

26. Larsen MJ, Nyvad B. Enamel erosion by soft drinks and orange juices relative to their $\mathrm{pH}$, buffering effect and contents of calcium phosphate. Caries Res 1999;33:81-87. 
27. Lodi CS, Sassaki KT, Fraiz FC, Delbem ACB, Martinhon CCR. Evaluation of some properties of fermented Milk beverages that affect the demineralization of dental enamel. Braz Oral Res 2010; 24(1):95-101.

28. Lussi A. Dental erosion. Clinical diagnosis and case history taking. Eur J Oral Sci 1996; 104:191-98.

29. Lussi A, Kohler N, Zero D, Schaffner M, Megert B. A comparison of the erosive potential of different beverages in primary and permanent teeth using an in vitro model. Eur J Oral Sci 2000;108:110-14.

30. Lussi A, Hellwig E. Erosive potential of oral care products. Caries Res 2001;35(suppl 1):52-56.

31. Lussi A, Jaeggi T. The potencial of various oral care products compared to foodstuffs and beverages. Schweiz Monatsschr Zahnmed 2001;111(3):274-81. [abstract]

32. Lussi A, Jaeggi T, Zero D. The role of diet in the aetiology of dental erosion. Caries Res 2004;38(suppl 1):34-44.

33. Lussi A, Jaeggi T. Dental erosion in children. Dental erosion: from diagnosis to therapy. Monographs in oral science. ISSN 0077-0892; 20:2006.

34. Lussi A, Schaffner M, Jaeggi T. Dental erosion - diagnosis and prevention in children and adults. Int Dent J 2007; 57:385-98.

35. Lussi A, Jaeggi T. Erosion-diagnosis and risk factors. Clin Oral Invest 2008; 12 (Suppl 1):S5-S13. 
36. Lussi A, Schlueter N, Rakhmatullina E, Ganss C. Dental erosion - an overview with emphasis on chemical and histopathological aspects. Caries Res 2011;45(suppl1):212.

37. McKnight-Hanes C, Whitford GM. Fluoride release from three glass ionomer materials and the effects of varnishing with or without finishing. Caries Res 1992;26(5):345-50.

38. Messias DC, Martins ME, Serra MC, Tursi CP. Feasibility of using sodium bicarbonate solution as a damage-limiting strategy for erosion lesions. Oral Health Prev Dent 2008; 6(2):155-8.

39. Messias DC, Turssi CP, Hara AT, Serra MC. Sodium bicarbonate solution as an antierosive agent against simulated endogenous erosion. Eur J Oral Sci 2010; 118 : 385-88.

40. Montgomery DC. Design and analysis of experiments. 1984.

41. Moynihan $P$. The interrelationship between diet and oral health. Proceedings of the Nutrition Society 2005; 64:571-80.

42. Nunn JH. Prevalence of dental erosion and the implications for oral health. Eur J Oral Sci 1996;104:156-61.

43. Pan American Health Organization/World Health Organization. Guiding principles for complementary feeding of the breastfed child. Division of health promotion and protection. Food and Nutrition Program. 2003; Washington/Geneva. 
44. Rugg-Gunn AJ, Maguire A, Gordon PH, McCabe JF, Stephenson G. Comparison of erosion of dental enamel by four drinks using an intra-oral applicance. Caries Res 1998;32:337-343

45. Rytömaa I, Meurman JH, Koskinen J, Laakso T, Gharazi L, Turunen R. In vitro erosion of bovine enamel caused by acids drinks and other foodstuffs. Scand J Dent Res 1988; 96: 324-33.

46. Schlueter N, Hara A, Shellis RP, Ganss C. Methods for the measurement and characterization of erosion in enamel and dentine. Caries Res 2011;45(suppl 1):1323.

47. Serra MC, Messias DCF, Turssi CP. Control of erosive tooth wear: possibilities and rationale. Braz Oral Res 2009;23(Spec Iss 1):49-55.

48. Shaw L, Smith AJ. Dental erosion - the problem and some practical solutions. British Dental Journal 1998; 186:115-18.

49. Silverstone LM, Saxton CA, Dogon IL, Fejerskov O. Variation in the pattern of acid etching of human dental enamel examined by scanning electron microscopy. Caries Res 1975;9(5):373-87.

50. Shellis RP, Ganss C, Ren Y, Zero DT, Lussi A. Methodology and models in erosion research: discussion and conclusions. Caries Res 2011; 45(suppl):69-77.

51. Sociedade Brasileira de Pediatria - Departamento Científico de Nutrologia. Manual de orientação para alimentação do lactente, do pré-escolar, do escolar, do adolescente e na escola. 2006. 
52. Thylstrup A, Fejerskov O. Diferentes conceitos da cárie dentária e suas implicações. In: cariologia clínica. São Paulo: Santos, v.2, p. 209-217. 2001.

53. Torres CP, Chinellati MA, Gomes-Silva JM, Rizóli FA, Oliveira MA, Palma-Dibb RG, Borsatto MC. Surface and subsurface erosion of primary enamel by acids beverage over time. Braz Dent J 2010; 21(4):337-45.

54. Vongsawan K, Surarit R, Rirattanapong P. The effect of high calcium milk and casein phosphopeptide-amorphous calcium phosphate on enamel erosion caused by cholinated water. Southeast Asian Journal of Tropical Medicine and Public Health 2010; 41(6):1494-99.

55. Wang X, Klocke A, Mihailova B, Tosheva L, Bismayer U. New insights into structural alteration of enamel apatite induced by citric acid and sodium fluoride solutions. J. Phys. Chem. B 2008:112, 8840-48.

56. Waterhouse PJ, Auad SM, Nunn JH, Steen IN, Moynihan PJ. Diet and dental erosion in young people in south-east Brazil. IJPD 2008;18:353-60.

57. West NX, Hughes JA, Addy M. The effect of $\mathrm{pH}$ on the erosion of dentine and enamel by dietary acids in vitro. Journal of Oral Rehabilitation 2001; 28:860-64.

58. Wiegand A, Attin T. Design of erosion/abrasion studies - insights and rational concepts. Caries Res 2011;45(suppl 1):53-59.

59. Wongkhantee S, Patanapiradej V, Maneenut C, Tantbirojn. Effect of acid food and drinks on surface hardness of enamel, dentine, and tooth-coloured filling materials. Journal of Dentistry 2006;34:214-20. 
60. World Health Organization. Diet, nutrition and the prevention of chronic diseases 2003.

61. World Health Organization. Complementary feeding. Infant and young child feeding Model Chapter for textbooks for medical students and allied health professionals 2009; 3:19-28.

62. Young A, Tenuta LMA. Initial Erosion Models. Caries Res 2011;45(suppl 1):33-42. 

APENDICE 



$$
\begin{array}{ll}
\text { Number of obs } & =612 \\
\text { Root MSE } & =39.0471
\end{array}
$$

R-squared $\quad=0.7046$

Adj R-squared $=0.6240$

\begin{tabular}{r|ccccc} 
Source & Partial SS & df & MS & F & Prob > F \\
\hline Model & 1745593.88 & 131 & 13325.1441 & 8.74 & 0.0000 \\
& & & & & \\
tratamento & 212939.036 & 5 & 42587.8073 & 6.26 & 0.0001 \\
bloco & 90884.8939 & 16 & 5680.30587 & 0.84 & 0.6426 \\
tratamento*bloco & 543956.035 & 80 & 6799.45044 & & \\
\hline tempo & 700433.504 & 5 & 140086.701 & 91.88 & 0.0000 \\
tempo*tratamento & 197380.413 & 25 & 7895.21654 & 5.18 & 0.0000 \\
& & & & & \\
Residual & 731844.506 & 480 & 1524.67606 & &
\end{tabular}



ANEXOS 



\section{ANEXO A - Comitê de Ética}

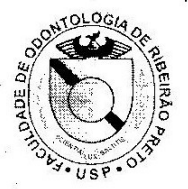

\section{UNIVERSIDADE DE SÃO PAULO}

Faculdade de Odontologia de Ribeiräo Preto

Comitê de Ética em Pesquisa

Of.ATAC.CEP/51611/FORP-USP/19.12.2011

Ref. processo n. ${ }^{\circ} \underline{\underline{2011.1 .1012 .58 .7}}$

Senhor(a) Pesquisador(a)

CAAE n. ${ }^{\circ} 0053.0 .138 .000-11$

Informamos que o Comitê de Ética em Pesquisa, em sua $126^{\circ}$ Sessão, realizada em 15 de dezembro de 2011, aprovou o desenvolvimento do projeto de pesquisa envolvendo seres humanos, intitulado. "Efeito dos alimentos e bebidas no esmalte dental deciduo após desafio erosivo com ácido cloridrico".

Na oportunidade, lembramos da necessidade de ser entregue, na secretaria do CEP, O Relatório Final em 15 de dezembro de 2012, com o respectivo formulário preenchido pelo pesquisador responsável.

Lembramos ainda que, quando da submissão do relatório a este Comitê quaisquer inclusōes ou modificaçōes no projeto original deverão ser comunicadas-e justificadas ao CEP, através do formulário supracitado.

$$
\text { Gackito }
$$

GISELE ELLENE ANDRADE DA DALTI

Secretária do Comitê de Ética em Pesquisa

IImo(a). $\operatorname{Sr}(a)$.

PG. KÉSSIA SUÊNIA FIDELIS DE MESQUITA (Profa. Dra. Maria Cristina Borsatto)

Departamento de Clínica Infantil, Odontologia Preventiva e Social

desta Faculdade

AVENIDA DO CAFÉ, S/N. O- TEL. (16) 3602-4123/3963-FAX(16) 3602-4102

14040-904 - RIBEIRÁO PRETO - SP - BRASIL 
86 Anexo

Ingredientes de acordo com as embalagens dos lanches:

ANEXO B - Papinha de Maçã
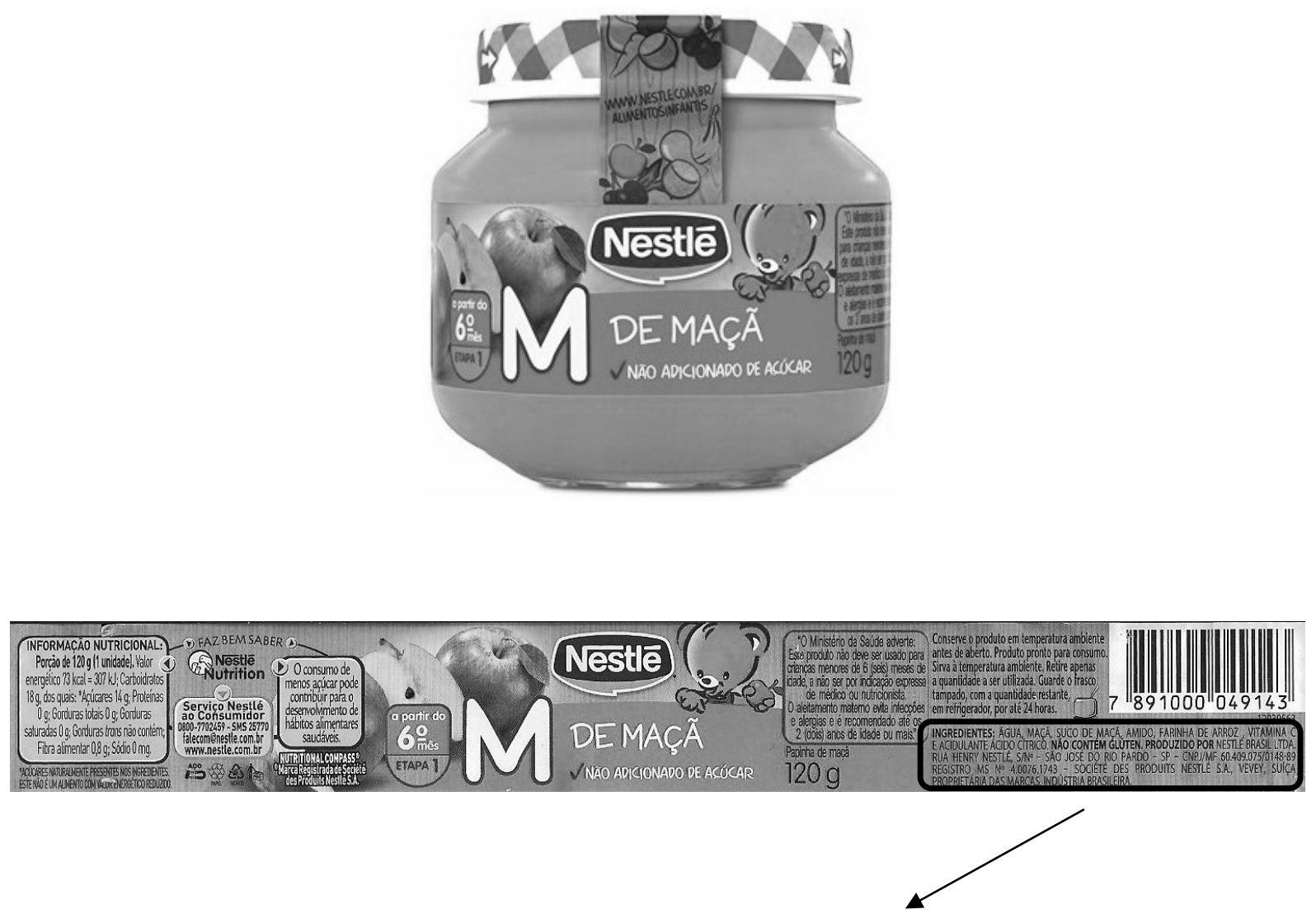

INGREDIENTES: AGUA, MACA SUCO DE MACA, AMIDO, FARINHA DE ARROZ, VITAMINA C E ACIDULANIE ACIDO CIIRCO NAO CONTEM GLUTEN. PRODUZIDO POR NESILE BRASILLTDA. RUA HENRY NESTLE, SINO - SAO JOSE DO RIO PARDO - SP - CNPJ/MF 60.409.075/0148-89 RESISTRO MS NO 4.0076.1743 - SOCIETE DES RRODUITS NESTLÉ S.A., VEVEY, SUIÇA PROPRIETARRIA DAS MARCAS INDUSTTRIA BRASIL FIRA. 


\section{ANEXO C - Leite AchocolatadoToddynho}

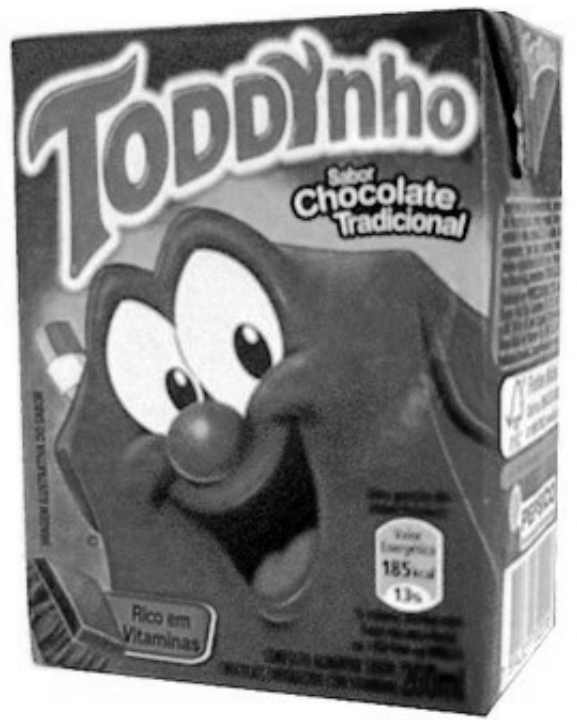

INFORMAÇÃO NUTRICIONAL

Porção de $200 \mathrm{ml}$ (1 unidade)

Quantidade por Porção ％ VD (*)

\begin{tabular}{|ccc|}
\hline $\begin{array}{c}\text { Valor Energético } \\
\text { Carboidratos }\end{array}$ & $32 \mathrm{~g}$, dos quais: & 9 \\
\hline Açúcares & $29 \mathrm{~g}$ & 11 \\
\hline Proteínas & $3,9 \mathrm{~g}$ & 5 \\
\hline Gorduras Totais & $4,7 \mathrm{~g}$ & 9 \\
\hline Gorduras & $2,1 \mathrm{~g}$ & 10 \\
\hline Saturadas & $0 \mathrm{~g}$ & \\
\hline Gorduras Trans & $0 \mathrm{~g}$ & 0 \\
\hline Fibra Alimentar & $130 \mathrm{mg}$ & 5 \\
\hline Sódio & $107 \mathrm{mg}$ & 11 \\
\hline Cálcio*** & $1,8 \mathrm{mg}$ & 13 \\
\hline Ferro *** & $135 \mathrm{mcg}$ \\
\hline Vitamina A & $9,0 \mathrm{mg}$ & 23 \\
\hline Vitamina C & $35 \mathrm{mcg}$ & 20 \\
\hline Ácido Fólico & \\
\hline Va & & 15 \\
\hline
\end{tabular}

$\%$ de Valores Diários de referência com base em uma dieta de $2.000 \mathrm{kcal}$ ou $8.400 \mathrm{~kJ}$. Seus valores diários podem ser maiores ou menores dependendo de suas necessidades energéticas.

** Valores diários não estabelecidos

${ }^{* * \star}$ Nutrientes naturalmente presente

Ingredientes: Leite integral reconstituído, açúcar, soro de leite em pó, cacau, gordura vegetal hidrogenada, extrato de malte, vitaminas (C, A, e ácido fólico), sal, espessantes: goma guar e carragena, estabilizantes: mono e diglicerídeos de ácidos graxos, citrato de sódio e lectina de soja, aromatizante. CONTÉM GLUTEN. 


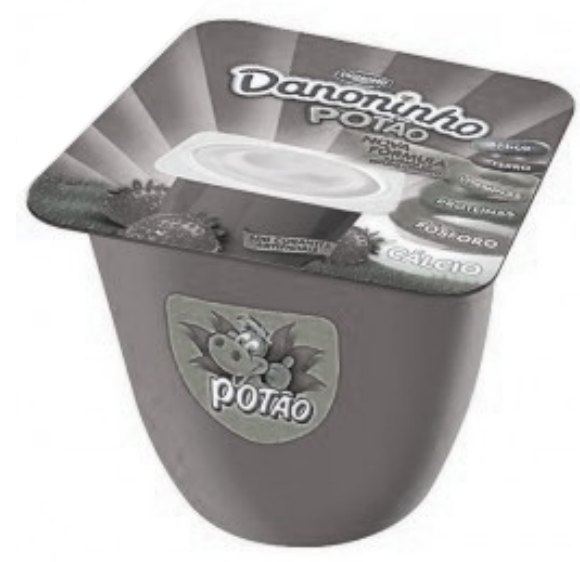

\begin{tabular}{|c|c|c|}
\hline \multicolumn{3}{|c|}{$\begin{array}{l}\text { Informação Nutricional } \\
\text { Porção de } 50 \mathrm{~g} \text { (1/2 pote) }\end{array}$} \\
\hline \multicolumn{2}{|c|}{ Quantidade por porção } & \multirow{2}{*}{$\begin{array}{c}\% \mathrm{VD}^{*} \\
3\end{array}$} \\
\hline Valor Energético & $55 \mathrm{kcal}=231 \mathrm{~kJ}$ & \\
\hline $\begin{array}{l}\text { Carboidratos, dos } \\
\text { quais: }\end{array}$ & $7,2 g$ & 2 \\
\hline $\begin{array}{l}\text { Açúcares } \\
\text { adicionados: }\end{array}$ & 5,79g & \\
\hline Proteínas & $3,2 g$ & 4 \\
\hline Gorduras Totais & 1,59 & 3 \\
\hline Gorduras Saturadas & $1,0 g$ & 5 \\
\hline Gorduras Trans & $0 \mathrm{~g}$ & $* *$ \\
\hline Fibra alimentar & $0 \mathrm{~g}$ & 0 \\
\hline Sódio: & $18 \mathrm{mg}$ & 1 \\
\hline $\begin{array}{l}\text { Sódio } \\
\text { adicionado: }\end{array}$ & Omg & \\
\hline VITAMINA D & $0,75 \mathrm{mcg}$ & 15 \\
\hline Vitamina $\mathrm{E}$ & $0,75 \mathrm{mg}$ & 8 \\
\hline CÁLCIO & $165 \mathrm{mg}$ & 17 \\
\hline Ferro & $1,1 \mathrm{mg}$ & 8 \\
\hline Zinco & $1,1 \mathrm{mg}$ & 15 \\
\hline Fósforo & $100 \mathrm{mg}$ & 14 \\
\hline $\begin{array}{l}\text { LEGENDA } \\
\text { "Valores diários de } r \\
\text { uma dieta de } 2.000 \mathrm{kc} \\
\text { valores diários poder } \\
\text { menores dependend } \\
\text { necessidades energe } \\
\text { " Valores diários nãd }\end{array}$ & $\begin{array}{l}\text { referência com be } \\
\text { cal ou } 8.400 \mathrm{KJ} \text {. S } \\
\text { m ser maiores ou } \\
\text { lo de suas } \\
\text { óticas. } \\
\text { o estabelecidos. }\end{array}$ & $\begin{array}{l}\text { ase em } \\
\text { ieus }\end{array}$ \\
\hline
\end{tabular}

Ingredientes: Leite Desnatado, Xarope de Açúcar, Preparado de Morango (Água, Frutose, Polpa de Morango, Cálcio, Fósforo, Açúcar, Amido Modificado, Zinco,Ferro, Vitaminas D e E, Estabilizantes Goma Xantana, Goma Carragena e Carboximetilcelulose. Acidulantes Ácido Tartárico e Ácido Cítrico, Aromatizante, Conservador Sorbato de Potássio e Corante Natural Carmim), Creme de Leite, Cálcio, Cloreto de Cálcio, Fermento Lácteo, Quimosina e Estabilizantes Goma Guar, Carboximetilcelulose, Goma Carragena e Goma Xantana. Contém Glúten. Pode conter traços de Castanha de Caju. 


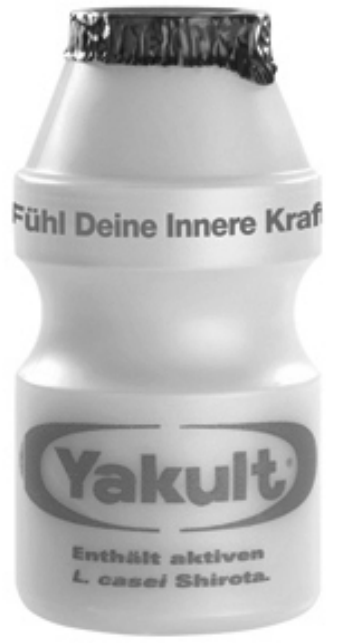

\section{INGREDIENTES}

Leite desnatado ejou leite desnatado reconstituído

Açúcar

Glicose

Fermento Lácteo

Aroma

NÃO CONTÉM GLÚTEN.

INFORMAÇÃO NUTRICIONAL

Porção 80g ( 1 unidade )

\begin{tabular}{|l|c|c|}
\hline \multicolumn{2}{|l|}{ Quantidade por porção } & $\% \mathrm{VD}(*)$ \\
\hline Valor energético & $51 \mathrm{kcal}=214 \mathrm{~kJ}$ & 3 \\
\hline Carboidratos & $11 \mathrm{~g}$ & 4 \\
\hline Proteínas & $1,6 \mathrm{~g}$ & 2 \\
\hline Cálcio & $69 \mathrm{mg}$ & 7 \\
\hline Sódio & $30 \mathrm{mg}$ & 1 \\
\hline
\end{tabular}

Conservação: Manter sob refrigeração ideal de $5^{\circ} \mathrm{C}$ (mínimo de $1^{\circ} \mathrm{C}$ e máximo de $10^{\circ} \mathrm{C}$ ).

"Não contém quantidades significativas de Gorduras totais, Gorduras Saturadas, Gorduras trans e Fibra Alimentar".

* \% Valores Diários com base em uma dieta de 2,000 kcal ou $8.400 \mathrm{~kJ}$. Seus valores diários podem ser maiores ou menores dependendo de suas necessidades. 


\section{ANEXO F - Suco de laranja}

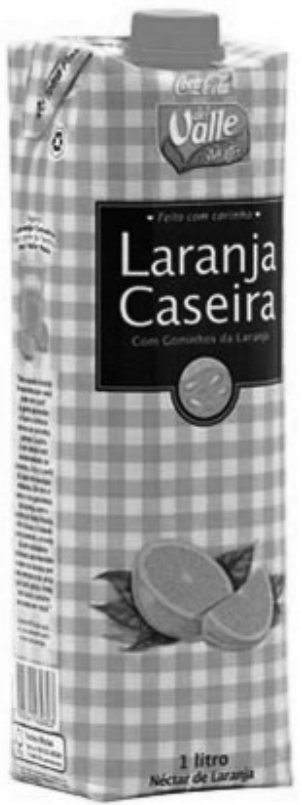

Néctar de Laranja Caseira

\section{INFORMAÇÃO NUTRICIONAL}

Porção de $200 \mathrm{ml}$ (1 copo)

Quantidade por porção

$\% \operatorname{VD}\left(^{*}\right)$

Valor energético

$108 \mathrm{kcal}=452 \mathrm{~kJ}$

5

Carboidratos

$26 \mathrm{~g}$

9

Não contém quantidade significativa de proteínas, gorduras saturadas, gorduras trans e fibra alimentar e sódio.

* \% valores Diários de referência com base em uma dieta de $2000 \mathrm{kcal}$ ou $8400 \mathrm{~kJ}$. Seus valores diários podem ser maiores ou menores, dependendo de suas necessidades energéticas. 


\section{ANEXO G - logurte de Morango}

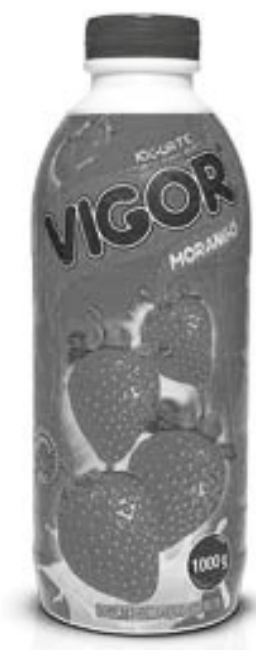

\section{Ingredientes:}

Leite desnatado, permeado de leite, açúcar, leitelho, preparado de morango (polpa de morango, açúcar, água, amido, aroma artificial de morango, corante natural carmim de cochonilha, espessante e estabilizante carragena, acidulante ácido cítrico e conservante sorbato de potássio), amido modificado, soro de leite em pó desnatado e fermento lácteo. AROMATIZADO ARTIFICIALMENTE. NÃO CONTÉM GLÚTEN.

\begin{tabular}{|c|c|c|}
\hline \multicolumn{3}{|c|}{$\begin{array}{l}\text { INFORMACCÕES NUTRICIONAIS } \\
\text { porção de 200ml (1 copo) }\end{array}$} \\
\hline & Quantidade por porção & $\% \operatorname{VD~}(*)$ \\
\hline Valor energético & $151 \mathrm{Kcal}=634 \mathrm{~kJ}$ & $8 \%$ \\
\hline Carboidratos & $33 g$ & $11 \%$ \\
\hline Proteínas & $4,4 g$ & $6 \%$ \\
\hline Sódio & $81 \mathrm{mg}$ & $3 \%$ \\
\hline Cálcio & $170 \mathrm{mg}$ & $17 \%$ \\
\hline
\end{tabular}

\$\% Valores Diários de referência com base em uma dietas de $200 \mathrm{Kcal}$ ou $8400 \mathrm{~kJ}$. Seus valores podem ser maiores ou menos dependendo de suas necessidades energéticas de suas necessidades energéticas. 